\title{
Dimerization of (+)-Myrmicarin 215B. A Potential Biomimetic Approach to Complex Myrmicarin Alkaloids
}

\author{
Alison E. Ondrus and Mohammad Movassaghi ${ }^{*}$ \\ Department of Chemistry, Massachusetts Institute of Technology, Cambridge, MA 02139, USA
}

\begin{abstract}
The acid promoted diastereoselective dimerization of myrmicarin $215 \mathrm{~B}$ is described. The reactivity of these sensitive alkaloids, structural assignment, and a possible mechanism for the observed dimerization are discussed. These finding raise the intriguing possibility of the synthesis of the highly sensitive myrmicarin alkaloids based on a strategy involving the direct dimerization of functional tricyclic myrmicarin derivatives.
\end{abstract}

\section{Introduction}

A series of structurally fascinating alkaloids have been isolated from the poison gland secretion of the African Myrmicaria opaciventris ant species (Figure 1). ${ }^{1}$ Through a series of elegant spectroscopic studies, the relative stereochemistry of myrmicarins $430 \mathrm{~A}$ (1) and 663 (2) has been assigned. These complex alkaloids were found to be highly sensitive to airoxidation, complicating their isolation. The high sensitivity of myrmicarin 430A (1) required its structural assignment as a crude mixture using phase-sensitive spectroscopic techniques. $1 \mathrm{c}$ The relative stereochemistry of myrmicarin $645(5)$ in addition to the absolute stereochemistry of complex myrmicarin alkaloids (i.e., 1, 2, and $\mathbf{5}$ ) is unknown. Another isomeric myrmicarin 430 was detected in the poison gland secretion but no structural information was reported. Interestingly, the paralytic activity of the poison gland secretion has been attributed to these intriguing alkaloids. ${ }^{1 \mathrm{~b}}$ A combination of their alluring molecular structure and the plethora of challenges associated with their sensitivity has prompted us to initiate a program directed toward the synthesis of the complex myrmicarin alkaloids. Herein we report our findings that raise the possibility of an efficient strategy for the synthesis of complex myrmicarins based on a vinyl pyrrole dimerization strategy.

Schröder and Francke have reported the spontaneous dehydration of a $\mathrm{C} 1$ '-C3 unsaturated derivative of myrmicarin 237 (Figure 1) to give myrmicarin $217(\mathbf{6}),{ }^{2}$ which they cite as strong evidence for the formation of tricyclic myrmicarins from simpler indolizine derivatives. Furthermore, they propose the possible dimerization of a doubly unsaturated indolizine derivative 9 (Scheme 1) to afford myrmicarin 430A (1) and other complex myrmicarin alkaloids. ${ }^{1 \mathrm{~b}}$

While the dimerization of 9 to give myrmicarin 430A (1) is plausible, we considered the possibility of tricyclic myrmicarin derivatives serving as direct precursors to $\mathbf{1}$. We propose

\footnotetext{
(C) 2009 Elsevier Science. All rights reserved

*Corresponding author. Tel.: (617) 253-3986; fax: (617) 252-1504; movassag@mit.edu
}

Publisher's Disclaimer: This is a PDF file of an unedited manuscript that has been accepted for publication. As a service to our customers we are providing this early version of the manuscript. The manuscript will undergo copyediting, typesetting, and review of the resulting proof before it is published in its final citable form. Please note that during the production process errors may be discovered which could affect the content, and all legal disclaimers that apply to the journal pertain. 
that an acid promoted dimerization of a suitable vinyl pyrroloindolizine derivative may lead directly to the fully substituted cyclopentane D-ring of myrmicarin 430A (1) as shown in Scheme 2 .

Specifically, our approach to the complex myrmicarin alkaloids is based on the hypothesis that C9-protonation of myrmicarin 215B (4) by a Brönsted acid (HA) would lead to reversible formation of the highly reactive azafulvenium ion $\mathbf{1 0}$ (Schemes 2 and 3). ${ }^{3} \mathrm{We}$ envisioned that C9-nucleophilic addition of myrmicarin 215B (4) to the C8-electrophilic center of the proposed azafulvenium ion $\mathbf{1 0}$ would result in the hexacyclic azafulvenium ion 11 (Scheme 3), exchanging a $\pi$-bond for a $\sigma$-bond. Intramolecular trapping of the intermediate azafulvenium ion $\mathbf{1 1}$ by $\mathrm{C} 8 \mathrm{~b}$-nucleophilic ${ }^{4}$ addition to $\mathrm{C} 1$-electrophilic center via transition state structure $\mathbf{1 2}$ was envisioned to give the iminium ion $\mathbf{1 3}$ as a heptacyclic precursor to myrmicarin 430A (1). The C8-deprotonation of iminium ion 13 would afford bis-enamine 14. Acid catalyzed tautomerization of the $\mathrm{C} 3 \mathrm{~b}$-enamine would provide the expected cis-azabicyclooctane core (the CD-ring system of $\mathbf{1}$ ) of myrmicarin 430A (1). Central to this strategy for the synthesis of complex myrmicarins was our proposed acid promoted cyclopentane annulation of vinyl pyrroloindolizine 4 (myrmicarin 215B), an unknown mode of reactivity for vinyl pyrroles. We envisioned isolation of the highly unstable myrmicarin 430A (1) either as an iminium ion salt (i.e. 13, Scheme 3) or as an appropriate derivative masking the sensitive enamine functional groups.

\section{Results and Discussion}

\subsection{Enantioselective synthesis of the tricyclic myrmicarins}

The implementation of this strategy for the preparation of complex myrmicarin alkaloids required the development of a versatile synthesis of tricyclic myrmicarin derivatives. We have recently reported a concise, enantioselective synthesis of all tricyclic myrmicarins (Scheme 4). 5,6 The key steps involve palladium-catalyzed coupling between triflate $\mathbf{1 9}$ and pyrrole 18, 7,8 copper-catalyzed enantioselective conjugate reduction of the resulting $\mathrm{N}$-vinyl pyrrole 17, 9,10 and a regioselective acid catalyzed Friedel-Crafts cyclization to provide the dihydroindolizine 15 (Scheme 4). ${ }^{5}$ Hydrogenation of the C6-C7 alkene in 15 (Scheme 4) and selective conversion of the tert-butyl ester to the corresponding primary iodide followed by a silver tetrafluoroborate promoted cyclization provides the tricyclic ketone $\mathbf{2 0}$ (Scheme 5). ${ }^{5}$ The final stages of the synthesis of myrmicarin 215B (4) involved reduction of the ketone 20 with lithium aluminum hydride at $0^{\circ} \mathrm{C}$ to afford the acid sensitive tricyclic alcohol 21 as an equal mixture of C8-epimers (Scheme 5). Acid catalyzed dehydration of alcohol 21 gave exclusively myrmicarin 215B (4). Alternatively, the reduction of ketone 20 to the C8alcohol followed by an acidic workup $(\mathrm{pH} 2)$ directly gave $4 .{ }^{5}$ The synthesis of the acid sensitive C8-C9 Z-alkene of myrmicarin 215A (3) was possible by an initial dehydration of ketone 20, using 2-chloro-3-ethylbenzoxazolium tetrafluoroborate, ${ }^{11}$ followed by partial hydrogenation with Lindlar catalyst. ${ }^{5}$ These stereoselective routes to the vinyl pyrroloindolizine structure provided access to the first pure samples of myrmicarins $215 \mathrm{~A}$ (3) and 215B (4). Complete reduction of the C3-carbonyl of 20 using lithium aluminum hydride at high temperature provided myrmicarin $217(\mathbf{6})$. The spectroscopic data for the synthetic alkaloids 3,4 , and $\mathbf{6}$ were found to be identical with those reported for natural isolates. $^{\text {b }}$

During the late operations in the synthesis of the tricyclic myrmicarins, we found the intermediates lacking the C8-ketone to be highly sensitive to both air oxidation and acid catalyzed decomposition. As noted in the isolation reports of myrmicarins 215 and 217, these compounds show significant air oxidation to the corresponding C6-C7 didehydro derivatives $213 \mathrm{~A} / \mathrm{B}$ and $215 \mathrm{C} .{ }^{1 \mathrm{~b}}$ In fact, we observed direct conversion of benzene- $d_{6}$ solutions of myrmicarins 215A, 215B, and 217 to myrmicarins 213A, 213B, and 215C, 
respectively, upon exposure to oxygen. Prolonged exposure to oxygen led to complete decomposition of both the tricyclic myrmicarins and their dehydrogenated derivatives. As a result, all manipulations of the tricyclic myrmicarin derivatives were conducted strictly under an argon atmosphere. ${ }^{12}$ Indeed, as a testament to their acid sensitivity, thin layer chromatography showed that brief exposure of myrmicarin 215A (3) to silica gel effected partial conversion to myrmicarin 215B (4).

\subsection{Acid-promoted reactivity of myrmicarin 215}

As an alternative to performing an acid catalyzed C8-C9 dehydration using an acidic aqueous work-up, completely stereoselective conversion of the alcohol 21 ( 1:1, C8epimers) to myrmicarin $215 \mathrm{~B}(4)$ was achieved by treatment of a benzene- $d_{6}$ solution $(0.05 \mathrm{M})$ of alcohol 21 with acetic acid (1.5 equiv) at ambient temperature. ${ }^{1} \mathrm{H}$ NMR monitoring of the reaction mixture led to the detection of the intermediate $\mathrm{C} 8$-acetate $\mathbf{2 2}$, likewise as an approximately equal mixture of $\mathrm{C} 8$-epimers. After $1 \mathrm{~h}$, trace amounts of myrmicarin 215B (4) were detected. Consumption of approximately $90 \%$ of the alcohol 21 occurred in $9 \mathrm{~h}$, at which point an equal mixture of acetate 22 and myrmicarin 215B (4) was observed. After an additional $61 \mathrm{~h}$, myrmicarin 215B (4) was the only significant component remaining in the sample. Failure to detect the putative azafulvenium ion 23 by ${ }^{1} \mathrm{H}$ NMR is consistent with its expected high reactivity and short lifetime. ${ }^{3}$

In contrast, treatment of a benzene- $d_{6}$ solution $(0.05 \mathrm{M})$ of alcohol 21 with trifluoroacetic acid (TFA, 1.10 equiv) effected full and clean conversion ( $\geq 90 \%$ by ${ }^{1} \mathrm{H}$ and ${ }^{13} \mathrm{C}$ NMR) to a single new product within $45 \mathrm{~min} .{ }^{1} \mathrm{H}$ NMR $(500 \mathrm{MHz})$ monitoring of the reaction mixture revealed that myrmicarin 215B (4) was formed immediately upon introduction of TFA and persisted in rapidly diminishing quantities until complete conversion to the new compound had occurred. Attempts to isolate this product after proper work-up or by direct crystallization were not successful due to rapid decomposition. However, under strictly moisture- and oxygen-free atmosphere the reaction mixture could be stored at subambient temperatures for $24 \mathrm{~h}$ without significant decomposition. ${ }^{13} \mathrm{C}$ NMR $(125 \mathrm{MHz})$ showed this compound to possess 30 chemically distinct carbons, the number expected for the desired dimerization product. Importantly, the same dimeric product could be obtained cleanly ( $\geq 90 \%$ by ${ }^{1} \mathrm{H}$ NMR) by direct treatment of a benzene- $d_{6}$ solution $(0.05 \mathrm{M})$ of myrmicarin 215B (4) with TFA (1.10 equiv). ${ }^{1} \mathrm{H}$ NMR $(500 \mathrm{MHz})$ monitoring of a benzene- $d_{6}$ solution $(0.05 \mathrm{M})$ of myrmicarin $215 \mathrm{~B}(4)$ with substoichiometric quantities of TFA revealed the extent of the conversion to the dimeric product was approximately equal to the amount of Brönsted acid additive, suggesting an acid promoted dimerization. By comparison, monitoring a dilute benzene- $d_{6}$ solution $(0.003 \mathrm{M})$ of myrmicarin $215 \mathrm{~B}(4)$ exposed to a large excess of TFA ( $>100$ equiv) gave less than $5 \%$ of the dimeric product. Instead we observed a mixture of pyrrole-ring protonated species over a period of several days. ${ }^{13,} 14 \mathrm{~A}$ basic work-up returned the starting myrmicarin 215B (4). Under these conditions, the neutral myrmicarin 215B (4) required to serve as the nucleophile in the dimerization process was not present in sufficient concentration for the reaction to occur. Notably, the dimerization of myrmicarin 215B (4) proceeds at low concentrations (i.e. $0.005 \mathrm{M}$ ) in the presence of stoichiometric quantities of acid.

Significantly, subjection of myrmicarin 215A (3) to these dimerization conditions (benzene$d_{6}, 0.01 \mathrm{M}, 23{ }^{\circ} \mathrm{C}, 5.5 \mathrm{~h}$ ) provided a compound that was identical by ${ }^{1} \mathrm{H}$ NMR to the dimeric product obtained from myrmicarin 215B (4). While a trace amount of myrmicarin 215B (4) was observed immediately after treatment with TFA, the monomer persisting throughout the reaction was exclusively myrmicarin $215 \mathrm{~A} \mathrm{(3)}$, suggesting that the $\mathrm{C} 8$-C9-alkene isomerization was slower than the subsequent acid promoted dimerization of myrmicarin 215B (4). Interestingly, the major myrmicarin 215 isomer isolated from the poison gland secretion is myrmicarin $215 \mathrm{~A}(\mathbf{3})$ and not myrmicarin $215 \mathrm{~B}(\mathbf{4}){ }^{1 \mathrm{~b}}$ 


\subsection{Synthesis and isolation of dimeric myrmicarins}

Due to the aforementioned instability of the acid promoted dimerization product of myrmicarin 215B (4) toward isolation, we attempted to assign its structure using a combination of gradient correlation (gCOSY) and heteronuclear single quantum correlation (HSQC) NMR experiments. Hence, we found the $\mathrm{C}_{30}$-dimeric compound to possess four methyl, thirteen methylene, and five methine units, as well as eight quaternary carbons. Compellingly, all of the resonances in the ${ }^{1} \mathrm{H}$ NMR spectrum occurred in the upfield region $(<\delta 3.57 \mathrm{ppm})$, attesting to the absence of the $\mathrm{C} 8-\mathrm{C} 9$ alkene present in the monomeric myrmicarins $215 \mathrm{~A} \mathrm{(3)}$ and 215B (4). Furthermore, the ${ }^{1} \mathrm{H}$ and ${ }^{13} \mathrm{C}$ NMR spectra contained one subset of that closely matched those of the tricyclic portion of myrmicarin 217 (6). Considering the intermediates in our proposed acid promoted dimerization of myrmicarin 215B (4), we speculated that the immediate dimeric product might be related to the iminium ion 13 (Scheme 3), a protonated tautomer of myrmicarin 430A (1). As the instability of the immediate dimerization product precluded an aqueous work-up, chromatographic purification, or crystallization, we examined reaction conditions that would provide a more stable, isolable derivative for thorough characterization.

Addition of hydrogen cyanide to a solution of the dimeric product to trap the putative iminium ion did not provide a stable derivative. ${ }^{15} \mathrm{We}$ reasoned that introduction of mild reducing agents would result in reduction of a reactive iminium ion or enamine functional group(s) that may be present in the dimerization product (i.e., C8a-iminium ion $\mathbf{1 3}$ or bisenamine 14, Scheme 3). Interestingly, sequential treatment of a benzene solution $(0.02 \mathrm{M})$ of either alcohol 21 or myrmicarin $215 \mathrm{~B}$ (4) with TFA $\left(1.10\right.$ equiv) for $4 \mathrm{~h}$ at $23^{\circ} \mathrm{C}$ followed by addition of sodium triacetoxyborohydride ( 6.50 equiv) in acetonitrile and mixing of the mixture (3.5:1, benzene:acetonitrile) for 3.5 hours at $23^{\circ} \mathrm{C}$, provided a compound with sufficient stability to undergo aqueous work-up (saturated aqueous ammonium hydrogen chloride solution), isolation, and chromatographic purification on silica gel. Significantly, this oxygen-sensitive compound obtained in 66\% isolated yield as a single diastereomer was consistent in all respects (HR-CIMS, ${ }^{1} \mathrm{H},{ }^{13} \mathrm{C}$, gCOSY, HSQC) with the hexacyclic dimer 24 (Scheme 7). The isolation of the dimer $\mathbf{2 4}$ as the sole product suggests a highly diastereoselective dimerization of myrmicarin 215B (4) in the initial bond forming event. The $\mathrm{C} 2$ - and $\mathrm{C} 3$-stereochemistry was later shown to be $(2 S, 3 R)$, as described below. The isolation of compound $\mathbf{2 4}$ is consistent with hydride reduction at $\mathrm{C} 1$ in either azafulvenium ion 11 (Scheme 3) or iminium ion $\mathbf{1 3}$ (Scheme 3). ${ }^{16}$

Although evidence for the first of the two carbon-carbon bond forming events in our proposed dimerization was compelling, we required a means of isolating a suitable derivative of the putative heptacyclic iminium ion to validate the formation of the second carbon-carbon bond, and to secure the presence of the fully substituted cyclopentane. The difficulties in the full structural characterization of the immediate TFA promoted dimerization product (due to its limited longevity) notwithstanding, in situ NMR correlation experiments of this compound provided valuable information. Importantly, while the assignment of all thirty signals in the ${ }^{13} \mathrm{C}$ NMR spectrum agreed reasonably well with the predicted values based on those of myrmicarin $430 \mathrm{~A}(\mathbf{1})$, the resonance assigned to position $\mathrm{C} 8 \mathrm{~b}$ in the putative iminium ion $\mathbf{1 3}$ (Scheme 4) occurred at an anomalously high chemical shift $(\delta 96.1 \mathrm{ppm})$. As this value was higher than expected for a quaternary carbon, we systematically considered alternative structures that would be more consistent with the data for the putative iminium ion (Scheme 8). While the anticipated $\mathrm{C} 1-\mathrm{C} 8 \mathrm{~b}$ bond formation would result in the heptacyclic iminium ion $\mathbf{1 3}$ (Scheme 8, path A), an alternate bond formation between $\mathrm{C} 1$ and $\mathrm{C} 3 \mathrm{~b}$ would provide the isomeric heptacyclic iminium ion $\mathbf{2 5}$ (Scheme 8, path B). ${ }^{17}$ In this scenario, the signal at $896.1 \mathrm{ppm}$ would be due to the $\mathrm{C} 3 \mathrm{~b}$ in the iminium ion 25 (Scheme 8). 
The spectroscopic data that we had obtained for the heptacyclic iminium ion was more consistent with a C1-C3b second bond formation to yield $\mathbf{2 5}$ (Scheme 8). To firmly establish the connectivity of the heptacyclic dimerization product, we investigated possible derivatives for further spectroscopic analysis. We reasoned that $\mathrm{C} 8$-deprotonation of the putative intermediate $\mathbf{2 5}$ (Scheme 8) with a strong base would provide the corresponding enamine that may exhibit enhanced stability relative to the iminium ion $\mathbf{2 5}$. Gratifyingly, we found that treatment of a benzene- $d_{6}$ solution of the dimeric iminium ion, prepared as described above, with excess resin-bound BEMP (2-tert-butylimino-2-diethylamino-1,3dimethyl-perhydro-1,3,2-diazaphosphorine, 10 equiv) under strictly oxygen-free conditions cleanly yielded a new $\mathrm{C}_{30}$-product as a solution in benzene- $d_{6}$. Importantly, the ${ }^{1} \mathrm{H}$ NMR $(500 \mathrm{MHz})$ of this species possessed a single resonance at $\delta 4.72 \mathrm{ppm}(1 \mathrm{H}, \mathrm{dd})$, which was consistent with an expected C8-methine of enamine 27 (Scheme 9, for stereochemical assignment see Figure 2). Addition of methanol- $d_{4}$ (15 equiv) to the solution of enamine 27 resulted in complete disappearance of the resonance at $\delta 4.72 \mathrm{ppm}$ over a period of $1.5 \mathrm{~h}$, consistent with the ${ }^{2} \mathrm{H} / \mathrm{H}$-exchange of an enamine. Unfortunately, the enamine 27 was unstable toward an aqueous work-up or attempted purification. While this presented challenges with regard to isolation or derivatization of enamine $\mathbf{2 7}$, its sensitivity was not surprising based on the reported difficulties associated with the closely related myrmicarin 430A (1). However, an isolable derivative could be obtained by hydrogenation (1 atm of dihydrogen over $5 \%$ palladium on carbon) of the diene $\mathbf{2 7}$ in benzene, which cleanly afforded the enamine $28 .{ }^{18}$ Thus without the need for isolation of sensitive intermediates, alcohol $\mathbf{2 1}$ was converted to enamine $\mathbf{2 8}$ in a single operation (87\%). ${ }^{19}$ Enamine $\mathbf{2 8}$ was sufficiently stable toward isolation in neat form but required storage under strictly inert atmosphere to avoid oxidative decomposition.

Similar to the previously isolated hexacycle 24 (Scheme 7), the ${ }^{1} \mathrm{H}$ and ${ }^{13} \mathrm{C}$ NMR spectra of both diene $\mathbf{2 7}$ and enamine $\mathbf{2 8}$ contained one set of resonances that closely resembled those of the tricyclic core of myrmicarin $217(6)$. Furthermore, the ${ }^{13} \mathrm{C}$ and ${ }^{1} \mathrm{H}-{ }^{13} \mathrm{C}$ HSQC NMR spectra of each compound showed the correct number of methine, methylene, methyl, and quaternary carbon units for structures $\mathbf{2 7}$ and $\mathbf{2 8}$ (Scheme 9). The presence of distinct C4-C8 and C1-C3 spin systems was recognized in the gCOSY spectra of both diene 27 and enamine 28. However, this data alone was not sufficient to distinguish between the two modes of cyclization (path A versus path B, Scheme 8) in the formation of these heptacyclic products. Additional data obtained using heteronuclear multiple bond correlation (HMBC) and nuclear Overhauser effect spectroscopy (NOESY) NMR (600 MHz) experiments allowed structural verification of products 27-29 (Scheme 9). The HMBC correlations (Figure 2A) in the spectrum of the enamine $\mathbf{2 8}$ were entirely consistent with the heptacyclic structure depicted in Scheme 9 (path B, Scheme 8). Correlations between C1-H/C4-H $\mathrm{H}_{\mathrm{c}}, \mathrm{C} 3 \mathrm{a}-$ $\mathrm{H} / \mathrm{C} 4-\mathrm{H}_{t}$, and $\mathrm{C} 3 \mathrm{a}-\mathrm{H} / \mathrm{C} 11-\mathrm{H}$ in the NOESY spectrum of enamine 28 validated this structural assignment. Additionally, NOESY correlations between $\mathrm{C} 1-\mathrm{H} / \mathrm{C} 10^{\prime}-\mathrm{H}, \mathrm{C} 2-\mathrm{H} / \mathrm{C} 3-\mathrm{H}$, and $\mathrm{C} 3 \mathrm{a} / \mathrm{C} 9$ provided the relative stereochemistry about the newly formed fully substituted cyclopentane ring (Figure 2B). ${ }^{20}$

We also sought derivatives that would be amenable to X-ray crystallographic analysis. Unfortunately, numerous attempts to crystallize the enamine $\mathbf{2 8}$ were unsuccessful. Even under strictly inert conditions extensive decomposition was observed within two days. Similar complications were present during manipulations of the corresponding protonated salts of enamine $\mathbf{2 8}$ formed upon treatment of $\mathbf{2 8}$ with a variety of Brönsted acids. In attempts to obtain derivatives with greater stability, we found that treatment of a benzene solution of the enamine 27 (Scheme 9) with benzoyl chlorides in the presence of excess diisopropylethylamine cleanly provided the corresponding C8-benzoylated products, many of which could be purified by silica gel chromatography. For example, in a single operation, the C8-p-bromobenzoylated product $\mathbf{2 9}$ was obtained in $67 \%$ yield starting with the alcohol 
$\mathbf{2 1}$ without isolation of iminium ion $\mathbf{2 6}$ or diene 27. Although the C8-p-bromobenzoylated and C8-p-iodobenzoylated products were found to be storable in the absence of oxygen, crystallization and co-crystallization attempts did not provide samples suitable for single crystal X-ray analysis. However, 2D-NMR analysis of these samples provided additional data that paralleled our earlier results with the enamine 28 (Figure 2). Specifically, the data obtained using the isolable $p$-bromobenzoylated product 29 (gCOSY, HSQC, HMBC, and NOESY) provided further support for the structural assignment of compounds 26-29. The signals at 96.1, 86.4, 83.6, and $86.9 \mathrm{ppm}$ in the ${ }^{13} \mathrm{C}$ NMR spectra of 26-29, respectively, were consistent with the C3b-tertiary amine. Since the hexacyclic dimer $\mathbf{2 4}$ is obtained by treatment of the iminium ion intermediate $\mathbf{2 6}$ with sodium triacetoxyborohydride, the $\mathrm{C} 2$ and $\mathrm{C} 3$-stereochemistry of $\mathbf{2 4}$ is assignment based on the relative stereochemistry found in the heptacyclic compounds 26-29.

A possible mechanism for the dimerization of myrmicarin 215B (4) to enamine 27 is presented in Scheme 10. The overall process may involve a stepwise C9-C8 bond formation to give $\mathbf{3 0}$ followed by $\mathrm{C} 3 \mathrm{~b}-\mathrm{C} 1$ bond formation to provide the iminium ion $31 .{ }^{21}$ The relative stereochemistry of the newly formed cyclopentane ring that is shared in compounds 26-29 suggests a convex face to convex face approach (i.e., 30, Scheme 10). Under the reaction conditions described above, $\pi$-stacking interactions between the putative electron deficient azafulvenium ion 10 and the approaching electron rich vinyl pyrroloindolizine (4), or the positioning of the counter ion $\left(\mathrm{A}^{-}\right.$, Scheme 10) with respect to the dimerization precursors may be responsible for the observed stereoselectivity. Hence, ongoing efforts are directed at modifying the reaction conditions and identifying an appropriate counter ion (i.e. formate) that may influence the mode of dimerization (Scheme 8). While the involvement of any biosynthetic machinery in the dimerization of $\mathrm{C} 15$ myrmicarin monomers to the more complex myrmicarins is unknown at this time, the observed high level of diastereoselection and efficiency in our acid promoted dimerization of myrmicarin 215B (4) highlights the possible direct dimerization of a pyrroloindolizine (i.e. 4) as the first step toward C30 and C45 derivatives.

\section{Conclusions}

TFA-promoted dimerization of (+)-myrmicarin 215B (4) leads to a sequence of highly efficient and stereoselective carbon-carbon bond forming events, providing the heptacyclic dimeric enamine 27 (Scheme 9). A possible mechanism for the diastereoselective dimerization of myrmicarin 215B (4) to this isomer of myrmicarin 430A (1), isomyrmicarin 430A (27), is presented (Scheme 10). The isolation of a single diastereomer of the heptacyclic products via the TFA promoted dimerization of myrmicarin 215 is noteworthy. These observations provide experimental data relevant to our proposed vinyl pyrroloindolizine dimerization strategy for the synthesis of the heptacyclic portion of complex myrmicarin alkaloids. Current efforts are directed at controlling the mode of dimerization (Scheme 8) for implementation of this strategy toward these highly sensitive compounds: a strategy with potential implications regarding the biogenesis of these structurally fascinating alkaloids.

\section{Experimental Section}

\subsection{General Procedures}

Reactions were performed in oven-dried or flame-dried round bottomed flasks or modified Schlenk (Kjeldahl shape) flasks. The flasks were fitted with rubber septa and reactions were conducted under a positive pressure of argon. NMR experiments were performed in vacuum-dried Wilmad Glass Co., Inc. 528-PP NMR tubes. Stainless steel syringes or cannulae were used to transfer air- and moisture-sensitive liquids. Flash column 
chromatography was performed as described by Still $^{22}$ using silica gel (60- $\AA$ pore size, $32-$ $63 \mu \mathrm{m}$, standard grade, Sorbent Technologies) or non-activated alumina gel (80-325 mesh, chromatographic grade, EM Science). Analytical thin-layer chromatography was performed using glass plates pre-coated with $0.25 \mathrm{~mm} 230-400$ mesh silica gel or neutral alumina gel impregnated with a fluorescent indicator $(254 \mathrm{~nm})$. Thin layer chromatography plates were visualized by exposure to ultraviolet light and/or by exposure to an ethanolic phosphomolybdic acid (PMA), an acidic solution of $p$-anisaldehyde (anis), an aqueous solution of ceric ammonium molybdate (CAM), an aqueous solution of potassium permanganate $\left(\mathrm{KMnO}_{4}\right)$ or an ethanolic solution of ninhydrin followed by heating $(<1 \mathrm{~min})$ on a hot plate $\left(\sim 250{ }^{\circ} \mathrm{C}\right)$. Organic solutions were concentrated on Büchi R-200 rotary evaporators at $\sim 20$ Torr (house vacuum) at $25-35{ }^{\circ} \mathrm{C}$, then at $\sim 1$ Torr (vacuum pump) unless otherwise indicated. Commercial reagents and solvents were used as received with the following exceptions: Dichloromethane, diethyl ether, tetrahydrofuran, acetonitrile and toluene was purchased from J.T. Baker (Cycletainer $\left.{ }^{\mathrm{TM}}\right)$ and were purified by the method of Grubbs et al. under positive argon pressure. ${ }^{23}$ Proton nuclear magnetic resonance $\left({ }^{1} \mathrm{H}\right.$ NMR) spectra were recorded with a Varian inverse probe 500 INOVA spectrometer or a Bruker inverse probe 600 Avance spectrometer. Chemical shifts are recorded in parts per million from internal tetramethylsilane on the $\delta$ scale and are referenced from the residual protium in the NMR solvent $\left(\mathrm{C}_{6} \mathrm{H}_{6}: \delta 7.16\right)$. Data is reported as follows: chemical shift [multiplicity ( $\mathrm{s}=$ singlet, $\mathrm{d}=$ doublet, $\mathrm{q}=$ quartet, $\mathrm{m}=$ multiplet $)$, coupling constant $(\mathrm{s})$ in Hertz, integration, assignment]. Carbon-13 nuclear magnetic resonance spectra were recorded with a Varian 500 INOVA spectrometer and are recorded in parts per million from internal tetramethylsilane on the $\delta$ scale and are referenced from the carbon resonances of the solvent (benzene- $d_{6}: \delta 128.0$ ). We thank Dr. Li Li for obtaining HRMS data at the Department of Chemistry Instrumentation Facility (MIT-DCIF). Infrared data were obtained with a PerkinElmer 2000 FTIR and are reported as follows: [frequency of absorption $\left(\mathrm{cm}^{-1}\right)$, intensity of absorption $(\mathrm{s}=$ strong, $\mathrm{m}=$ medium, $\mathrm{w}=$ weak, $\mathrm{br}=$ broad $)$, assignment $]$.

\subsubsection{Tricyclic alcohol 21}

Solid lithium aluminum hydride ( $11.6 \mathrm{mg}, 306 \mu \mathrm{mol}, 6.00$ equiv) was added in a single portion to a solution of tricyclic ketone $\mathbf{2 0}\left(11.8 \mathrm{mg}, 51.0 \mu \mathrm{mol}, 1\right.$ equiv) in $\mathrm{Et}_{2} \mathrm{O}(950 \mu \mathrm{L})$ at $-78{ }^{\circ} \mathrm{C}$ followed by immediate placement of the reaction flask on an ice-water bath. After $40 \mathrm{~min}$, the vigorously stirred grey suspension was cooled to $-78^{\circ} \mathrm{C}$ and excess hydride was quenched by the slow addition of water $(1.20 \mathrm{~mL})$ via syringe. The cold bath was immediately removed and the mixture allowed to warm to $23{ }^{\circ} \mathrm{C}$. The pale grey suspension was diluted sequentially with a 6-mL portion of $\mathrm{Et}_{2} \mathrm{O}$ and a saturated aqueous solution of Rochelle salt $(6 \mathrm{~mL})$, and the two-phase mixture was vigorously stirred. After $3 \mathrm{~h}$, the resulting slightly opaque aqueous layer was separated from the clear and colorless organic layer and was extracted with EtOAc $(3 \times 5 \mathrm{~mL})$. The combined organic layers were washed with a 5-mL portion of brine, dried over anhydrous sodium sulfate, filtered, and concentrated under reduced pressure to give exclusively the alcohol $\mathbf{2 1}$ as a colorless oil (10.9 $\mathrm{mg}, 100 \%) .{ }^{1} \mathrm{H}$ NMR analysis revealed the product to be a mixture of C8-epimers (3:2). The alcohol 21 was found to be exceedingly sensitive toward dehydration and decomposition upon treatment with silica or alumina gel and required storage under an argon atmosphere. ${ }^{1} \mathrm{H}$ NMR $\left(500 \mathrm{MHz}, \mathrm{C}_{6} \mathrm{D}_{6}, 23^{\circ} \mathrm{C}, 3: 2\right.$ mixture of epimers, major epimer denoted by *), $\delta: 4.71\left(\mathrm{dd}, 1 \mathrm{H}, J=7.6,5.8 \mathrm{~Hz}, \mathrm{C} 8-\mathrm{H}^{*}\right), 4.70(\mathrm{dd}, 1 \mathrm{H}, J=7.2,6.3 \mathrm{~Hz}, \mathrm{C} 8-$ H), 3.19-3.27 (m, 2H, C4a-H*, C4a-H), 2.74 (dd, 1H, J = 14.6, 7.9 Hz, C7-H*), 2.53-2.70 (m, 9H, C3-H*, C3-H, C3-H*, C3-H, C11-H*, C11-H, C11-H'*, C11-H', C7-H), 2.31-2.41 (m, 2H, C7-H*, C7-H), 2.00-2.09 (m, 2H, C4-H*, C4-H), 1.90-1.99 (m, 4H, C9-H*, C9-H, C9-H' *, C9-H'), 1.65-1.72 (m, 2H, C6-H, C6-H), 1.50-1.60 (m, 4H, C4-H*, C4-H, C5-H*, C5-H), 1.31 (t, 3H, $\left.J=7.5 \mathrm{~Hz}, \mathrm{C} 12-\mathrm{H}^{*}\right), 1.28$ (t, 3H, $\left.J=7.6 \mathrm{~Hz}, \mathrm{C} 12-\mathrm{H}\right), 1.12$ (t, $3 \mathrm{H}, J=$ $7.3 \mathrm{~Hz}, \mathrm{C} 10-\mathrm{H}), 1.11$ (t, 3H, J = 7.3 Hz, C10-H*), 0.79-0.90 (m, 2H, C5-H*, C5-H). ${ }^{13} \mathrm{C}$ 
NMR (500 MHz, $\mathrm{C}_{6} \mathrm{D}_{6}, 23^{\circ} \mathrm{C}, 3: 2$ mixture of epimers, major epimer denoted by $\left.*\right), \delta$ : $127.7^{*}, 127.6,121.6^{*}, 121.6,118.9^{*}, 118.5,118.3^{*}, 118.3,70.0^{*}, 69.7,55.3^{*}, 55.2,37.2^{*}$, $37.4,31.5^{*}, 32.4,30.2 *, 30.2,26.3^{*}, 26.3,23.2^{*}, 23.1,20.9 *, 20.9,19.2 *, 19.1,17.2 *, 17.3$, 11.8, 11.7*. FTIR (neat), cm ${ }^{-1}: 3417$ (br-s, O-H), 2597 (s, C-H), 2854 (s, C-H), 1454, 1320, 1044. HRMS (ESI): $m / z$ calcd for $\mathrm{C}_{15} \mathrm{H}_{23} \mathrm{NONa}[\mathrm{M}+\mathrm{Na}]^{+}: 256.1672$; Found: 256.1677 . TLC (alumina gel, 30\% EtOAc-hexanes), $R_{\mathrm{f}}: 0.26,0.30\left(\mathrm{UV}, \mathrm{KMnO}_{4}\right)$.

\subsubsection{Hexacyclic dimer 24}

A sample of alcohol 21 ( $3.4 \mathrm{mg}, 14.6 \mu \mathrm{mol}, 1$ equiv) was dried by concentration from anhydrous benzene- $d_{6}(3 \times 350 \mu \mathrm{L})$. The residue was dissolved in benzene- $d_{6}(650 \mu \mathrm{L})$ and was purged by a stream of argon for $3 \mathrm{~min}$. A solution of TFA $(1.2 \mu \mathrm{L}, 16.0 \mu \mathrm{mol}, 1.10$ equiv) in benzene- $d_{6}(51.2 \mu \mathrm{L})$ was added drop wise via syringe. The resulting solution became intense yellow immediately upon addition of TFA and faded to a tan color within 2 min. The mixture was mixed and maintained under an argon atmosphere for $4.5 \mathrm{~h}$. A suspension of sodium triacetoxyborohydride $(20.1 \mathrm{mg}, 94.9 \mu \mathrm{mol}, 6.50$ equiv) in acetonitrile- $d_{3}(200 \mu \mathrm{L})$ was then added via syringe and the resulting pale burgundy suspension was stirred under inert atmosphere. After $3.5 \mathrm{~h}$, the suspension was diluted with EtOAc $(7.5 \mathrm{~mL})$ and the resulting mixture was washed with saturated aqueous ammonium chloride solution $(4 \mathrm{~mL})$. The clear, colorless aqueous layer was separated and extracted with ethyl acetate $(3 \times 3 \mathrm{~mL})$ and the combined pale yellow organic solution was washed with saturated aqueous sodium bicarbonate $(3 \mathrm{~mL})$, and brine $(3 \mathrm{~mL})$. The organic layer was dried over anhydrous sodium sulfate, and then concentrated under reduced pressure to give a deep brown residue. Purification of the residue by silica gel column chromatography ( $5 \%$ EtOAc-hexanes; diameter $0.5 \mathrm{~cm}$, height $4.5 \mathrm{~cm}$ ) gave the hexacyclic dimer 24 as a yellow oil (2.1 mg, 66\%). ${ }^{24}{ }^{1} \mathrm{H}$ NMR (500 MHz, $\left.\mathrm{C}_{6} \mathrm{D}_{6}, 23{ }^{\circ} \mathrm{C}\right), \delta: 3.36(\mathrm{~m}, 2 \mathrm{H}, \mathrm{C} 4 \mathrm{a}$ '-H, C5a'-H), 3.15 (dd, 1H, J = 13.4, $2.7 \mathrm{~Hz}, \mathrm{C} 1-\mathrm{H}), 2.80$ (m, 1H, C3-H), 2.79 (m, 1H, C3'-H/C4-H), 2.63-2.73 (m, 9H, C3'-H/C4-H, C11-H, C11'-H, C3'-H/C4-H, C7'-H, C8-H, C3'-H/C4-H), 2.46 (m, 2H, C7'-H, C8-H), 2.35 (dd, 1H, J = 13.4, 10.8 Hz, C1-H'), 2.20 (m, 1H, C2-H), 2.06 (m, 1H, C4'-H/C5-H), 2.01 (m, 1H, C4'-H/C5-H), 2.01 (m, 1H, C9-H), 1.93 (m, 1H, C9-H'), 1.71 (m, 2H, C6'-H/C7-H), 1.67 (m, 1H, C4'-H/C5-H), 1.59 (m, 1H, C4'-H/C5-H), 1.57 (m, 2H, C5'-H, C6-H), 1.46 (t, 3H, $\left.J=7.5 \mathrm{~Hz}, \mathrm{C} 12-\mathrm{H} / \mathrm{C} 12^{\prime}-\mathrm{H}\right), 1.43$ (t, 3H, J = 7.5 Hz, C12-H/C12'-H), 1.42 (m, 1H, C6'-H/C7-H), 1.35 (m, 1H, C6'-H/C7-H), 1.26 (d, 3H, J = 6.7 $\left.\mathrm{Hz}, \mathrm{C} 10^{\prime}-\mathrm{H}\right), 1.11$ (t, 3H, J = 7.3 Hz, C10-H), 0.91 (m, 1H, C5'-H/C6-H), 0.88 (m, 1H, C5'H/C6-H). ${ }^{13} \mathrm{C}$ NMR (125.8 MHz, $\left.\mathrm{C}_{6} \mathrm{D}_{6}, 23{ }^{\circ} \mathrm{C}\right), \delta: 128$ (C2a'/C3b), 126.8 (C2a'/C 3b), 122.7 (C1'/C8b), 121.8 (C1'/C8b), 118.6 (C7a'/C8a), 118.3 (C7a'/C8a), 116.5 (C2'/C3a), 114.1 (C2'/C3a), 55.4 (C4a'/C5a), 55.2 (C4a'/C5a), 44.9 (C3), 42.1 (C2), 37.6 (C4', C5), 31.3 (C1), 30.6 (C5'/C6), 30.3 (C5'/C6), 27.4 (C3'/C4), 25.6 (C3'/C4), 25.2 (C9), 23.3 (C6'/C7), 23.2 (C6'/C7), 21.3 (C7'/C8), 21.2 (C7'/C8), 19.3 (C11/C11'), 19.3 (C11/C11'), 18.2 (C10'), 17.0 (C12, C12' $), 13.8$ (C10). FTIR (neat), cm ${ }^{-1}: 2928$ (s, C-H), 2852 (s, C-H), 1737, 1688, 1458, 1321, 1261, 1197. HRMS (ESI): $m / z$ calcd for $\mathrm{C}_{30} \mathrm{H}_{44} \mathrm{~N}_{2}[\mathrm{M}+\mathrm{H}]^{+}: 433.3577$; Found: 433.3441. TLC (silica gel, 10\% EtOAc-hexanes), $R_{\mathrm{f}}: 0.53$ (UV, anis).

\subsubsection{Iminium salt 26}

A sample of myrmicarin $215 \mathrm{~B}(4,5.5 \mathrm{mg}, 25.6 \mu \mathrm{mol}, 1$ equiv) was dried by concentrated from anhydrous benzene $(3 \times 350 \mu \mathrm{L})$. The residue was dissolved in benzene- $d_{6}(600 \mu \mathrm{L})$ in an NMR tube fitted with a rubber septum and was purged by a gentle stream of argon for 3 min. A solution of TFA $(2.2 \mu \mathrm{L}, 29.4 \mu \mathrm{mol}, 1.15$ equiv $)$ in benzene- $d_{6}(52.7 \mu \mathrm{L})$ was added drop-wise via syringe. The resulting reaction mixture became intense yellow immediately upon addition of the TFA solution and gradually turned brown over $30 \mathrm{~min}$. The sample was mixed and maintained under an argon atmosphere for $4.5 \mathrm{~h}$ at ambient temperature. ${ }^{1} \mathrm{H}$ NMR analysis revealed complete conversion of myrmicarin $215 \mathrm{~B}(4)$ to the highly airsensitive iminium salt $\mathbf{2 6}$. This compound was found to be unstable toward isolation. The 
same dimerization product $\mathbf{2 6}$ was obtained starting with the alcohol $\mathbf{2 1}$ in place of myrmicarin $215 \mathrm{~B}(\mathbf{4})$ following a similar protocol. ${ }^{1} \mathrm{H}$ NMR $\left(500 \mathrm{MHz}, \mathrm{C}_{6} \mathrm{D}_{6}, 23{ }^{\circ} \mathrm{C}\right), \delta$ : 3.57 (tdd, $\left.1 \mathrm{H}, J=10.5,4.9,3.7 \mathrm{~Hz}, \mathrm{C} 4 \mathrm{a}^{\prime}-\mathrm{H}\right), 2.82$ (m, 1H, C8-H), 2.77 (m, 1H, C8-H'), 2.73 (m, 1H, C5a-H), 2.54 (m, 1H, C7'-H), 2.54 (d, 1H, J = 9.8 Hz, C1-H), 2.45 (m, 1H, C11'-H), 2.39 (m, 1H, C11'-H'), 2.35 (m, 1H, C3-H), 2.34 (m, 1H, C4'-H), 2.31 (m, 1H, C5-H), 2.29 $\left(\mathrm{m}, 1 \mathrm{H}, \mathrm{C}^{\prime}-\mathrm{H}\right), 2.29$ (m, 1H, C2-H), 2.29 (m, 1H, C3'-H), 2.24 (q, 2H, J = 7.6 Hz, C11-H), 2.05 (tdd, $\left.1 \mathrm{H}, J=14.3,10.7,6.3 \mathrm{~Hz}, \mathrm{C} 3^{\prime}-\mathrm{H}\right), 1.81$ (m, 1H, C7-H), 1.68 (m, 1H, C6'-H), 1.68 (m, 1H, C5-H), 1.64 (m, 1H, C5'-H), 1.60 (m, 1H, C4'-H), 1.54 (m, 1H, C4-H), 1.47 (m, 1H, C4-H'), 1.45 (m, 1H, C6'-H), 1.35 (m, 1H, C6-H), 1.29 (m, 1H, C9-H), 1.22 (m, 1H, C7$\left.\mathrm{H}^{\prime}\right), 1.19$ (t, 3H, J = 7.5 Hz, C12'-H), 1.08 (m, 1H, C9-H'), 1.06 (t, 3H, J=7.6 Hz, C12-H), 0.88 (m, 1H, C6-H'), 0.81 (t, 3H, $J=7.5 \mathrm{~Hz}, \mathrm{C} 10-\mathrm{H}), 0.77$ (m, 1H, C5'-H), 0.74 (d, 3H, $J=$ $\left.6.7 \mathrm{~Hz}, \mathrm{C} 10^{\prime}-\mathrm{H}\right) .{ }^{13} \mathrm{C}$ NMR (125.8 MHz, $\left.\mathrm{C}_{6} \mathrm{D}_{6}, 23{ }^{\circ} \mathrm{C}\right), \delta: 187.1$ (C8a), 181.0 (C3a), 137.2 (C8b), 127.1 (C2a'), 121.7 (C1'), 119.4 (C7a'), 111.3 (C2'), 96.1 (C3b), 55.7 (C5a), 55.6 (C4a'), 51.7 (C2), 45.9 (C1), 45.2 (C3), 38.0 (C4), 37.7 (C4'), 36.7 (C5), 29.7 (C5'), 27.0 (C6), 27.0 (C3'), 26.4 (C8), 22.7 (C6'), 21.0 (C9), 20.9 (C7'), 18.6 (C7), 18.6 (C11'), 18.3 (C11), 17.1 (C12'), 16.7 (C10'), 14.0 (C12), 13.3 (C10).

\subsubsection{Heptacyclic diene 27}

A sample of alcohol 21 (5.1 mg, $21.9 \mu \mathrm{mol}, 1$ equiv) was dried by concentration from anhydrous benzene $(3 \times 350 \mu \mathrm{L})$. The residue was dissolved in benzene- $d_{6}(600 \mu \mathrm{L})$ in an NMR tube fitted with a rubber septum and was purged by a gentle stream of argon for 3 min. A solution of TFA $(1.8 \mu \mathrm{L}, 24.1 \mu \mathrm{mol}, 1.10$ equiv $)$ in benzene- $d_{6}(52.1 \mu \mathrm{L})$ was added drop wise via syringe. The resulting reaction mixture became intense yellow immediately upon addition of the TFA and faded to a tan color within 2 min. The sample was mixed and maintained under an argon atmosphere for $4.5 \mathrm{~h}$ at ambient temperature. Monitoring of the reaction mixture by ${ }^{1} \mathrm{H}$ NMR revealed complete consumption of alcohol 21 and myrmicarin 215B (4, generated in situ). The contents of the sample were transferred to a recovery flask under an inert atmosphere (glove-box, nitrogen atmosphere) and the transfer completed with three $50-\mu \mathrm{L}$ benzene- $d_{6}$ rinses. A single portion of resin-bound BEMP $(99.0 \mathrm{mg}, 2.2 \mu \mathrm{mol} /$ $\mathrm{mg}$ on 200-400 mesh polystyrene resin, 10.0 equiv) was added to the solution of the iminium salt $\mathbf{2 6}$ and the resulting pale yellow suspension was stirred for 30 min under strictly inert conditions. The suspension was filtered through a cotton plug, the filter-cake was rinsed with benzene- $d_{6}(3 \times 150 \mu \mathrm{L})$, and the pale yellow solution was sealed in a recovery flask under a nitrogen atmosphere, placed on a vacuum manifold and concentrated to $\sim 350 \mu \mathrm{L}$. The transfer of this solution via cannula into a sealed, argon-purged NMR tube and using two additional portions of benzene- $d_{6}(150 \mu \mathrm{L})$ to complete the transfer, provided a clear, faintly yellow solution of the exceedingly air-sensitive diene 27 suitable for ${ }^{1} \mathrm{H}$ NMR and ${ }^{13} \mathrm{C}$ NMR analysis. ${ }^{1} \mathrm{H}$ NMR $\left(500 \mathrm{MHz}, \mathrm{C}_{6} \mathrm{D}_{6}, 23{ }^{\circ} \mathrm{C}\right), \delta: 4.72(\mathrm{dd}, 1 \mathrm{H}, J=7.2$, $3.2 \mathrm{~Hz}, \mathrm{C} 8-\mathrm{H}), 3.46$ (tdd, $\left.1 \mathrm{H}, J=10.9,5.4,3.8 \mathrm{~Hz}, \mathrm{C} 4 \mathrm{a}^{\prime}-\mathrm{H}\right), 3.00$ (m, 1H, C3'-H), 3.00 (m, 1H, C5a-H), 2.70 (dd, J =15.4, 7.5 Hz, 1H, C3'-H), 2.68 (m, 1H, C7'-H), 2.67 (q, 2H, $J=$ $\left.7.6 \mathrm{~Hz}, \mathrm{C} 11^{\prime}-\mathrm{H}\right), 2.60$ (d, 1H, $\left.J=10.7 \mathrm{~Hz}, \mathrm{C} 1-\mathrm{H}\right), 2.50$ (ddd, 1H, J = 16.0, 11.8, 6.3 Hz, C7'H), $2.48(\mathrm{~m}, 1 \mathrm{H}, \mathrm{C} 3-\mathrm{H}), 2.34(\mathrm{dq}, 1 \mathrm{H}, J=13.8,7.5 \mathrm{~Hz}, \mathrm{C} 11-\mathrm{H}), 2.26(\mathrm{dq}, 1 \mathrm{H}, J=13.8,7.5$ Hz, C11-H'), 2.26 (m, 1H, C2-H), 2.21 (m, 1H, C7-H), 2.16 (m, 1H, C5-H), 2.15 (m, 1H, C7-H'), 2.08 (dt, 1H, J=11.5, 5.8 Hz, C4'-H), 1.85 (td, 1H, J=11.5, 7.8 Hz, C4-H), 1.75 (m, 1H, C4-H'), 1.71 (m, 1H, C6-H), 1.69 (m, 1H, C6'-H), 1.68 (m, 1H, C5-H'), 1.65 (m, 1H, C4'-H), 1.53 (m, 1H, C5'-H), 1.50 (m, 1H, C9-H), 1.39 (m, 1H, C6'-H), 1.38 (t, 3H, J = $\left.7.6 \mathrm{~Hz}, \mathrm{C} 12^{\prime}-\mathrm{H}\right), 1.31$ (m, 1H, C9-H'), 1.24 (t, 3H, $\left.J=7.5 \mathrm{~Hz}, \mathrm{C} 12-\mathrm{H}\right), 1.09$ (tdd, 1H, $J=$ 11.9, 4.9, 1.4 Hz, C6-H'), 1.04 (d, 3H, J=6.7 Hz, C10'-H), 1.00 (t, 3H, J=7.3 Hz, C10-H), 0.88 (tdd, $\left.1 \mathrm{H}, J=12.8,10.9,2.0 \mathrm{~Hz}, \mathrm{C} 5^{\prime}-\mathrm{H}\right) .{ }^{13} \mathrm{C}$ NMR $\left(125.8 \mathrm{MHz}, \mathrm{C}_{6} \mathrm{D}_{6}, 23{ }^{\circ} \mathrm{C}\right), \delta: 152.9$ (C8a), 152.3 (C3a), 132.7 (C8b), 128 (C2a'), 121.9 (C1'), 116.7 (C7a'), 114.2 (C2'), 88.0 (C8), 86.4 (C3b), 55.5 (C4a'), 54.8 (C5a), 50.3 (C2), 49.4 (C1), 44.8 (C3), 41.3 (C4), 37.3 
(C4'), 36.2 (C5), 30.6 (C6), $30.2\left(\mathrm{C5}^{\prime}\right), 27.9$ (C3'), $23.3\left(\mathrm{C6}^{\prime}\right), 22.7$ (C7), $21.3\left(\mathrm{C}^{\prime}\right), 20.8$

(C9), 19.4 (C11), 19.2 (C11'), 17.6 (C12'), 16.3 (C10'), 14.8 (C12), 13.9 (C10).

\subsubsection{Heptacyclic Enamine 28}

A sample of alcohol 21 (10.0 mg, $42.9 \mu \mathrm{mol}, 1$ equiv) was dried by concentration from anhydrous benzene $(3 \times 500 \mu \mathrm{L})$. The residue was dissolved in benzene $(1.06 \mathrm{~mL})$ and was purged by a stream of argon for $3 \mathrm{~min}$. A solution of TFA $(3.5 \mu \mathrm{L}, 47.2 \mu \mathrm{mol}, 1.10$ equiv) in benzene $(23.5 \mu \mathrm{L})$ was added drop-wise via syringe. The resulting solution became intense yellow immediately upon addition of TFA and faded to a clear tan color within $2 \mathrm{~min}$. The mixture was mixed and maintained under an argon atmosphere for $4.5 \mathrm{~h}$. The contents of the sample were transferred to a recovery flask under an inert atmosphere (glove-box, nitrogen atmosphere) and the transfer completed with three $50-\mu \mathrm{L}$ benzene- $d_{6}$ rinses. A single portion of resin-bound BEMP (195 mg, $2.2 \mu \mathrm{mol} / \mathrm{mg}$ on 200-400 mesh polystyrene resin, 10.0 equiv) was added to the solution of the iminium ion salt $\mathbf{2 6}$ and the resulting pale yellow suspension was stirred for 30 min under strictly inert conditions. The suspension was filtered through a cotton plug and the filter-cake was rinsed with benzene $(3 \times 450 \mu \mathrm{L})$ to give a solution of the diene 27. Palladium on activated carbon $(20.0 \mathrm{mg}, 5 \%-\mathrm{Pd} / \mathrm{C})$ was added and the flask was sealed under nitrogen and removed from the glove-box. The reaction vessel was flushed with dihydrogen ( 1 atm) for $5 \mathrm{~min}$ and then maintained under a balloonpressure of dihydrogen for an additional $30 \mathrm{~min}$ at ambient temperature. Dilution of the black suspension with EtOAc $(2 \mathrm{~mL})$, and filtration of the mixture through a plug of celite (diam $0.6 \mathrm{~cm}$, ht. $4.0 \mathrm{~cm}$ ), followed by an EtOAc rinse $(15 \mathrm{~mL})$, yielded a clear yellow solution of the desired enamine 28. Removal of the volatiles under reduced pressure gave the pure enamine $\mathbf{2 8}(8.1 \mathrm{mg}, \mathbf{8 7 \%})$ as a clear yellow oil with marginal stability. This enamine was sufficiently stable toward isolation in neat form but required storage under strictly inert atmosphere to avoid oxidative decomposition; spectroscopic characterization was conducted shortly after isolation. ${ }^{1} \mathrm{H}$ NMR $\left(500 \mathrm{MHz}, \mathrm{C}_{6} \mathrm{D}_{6}, 23{ }^{\circ} \mathrm{C}\right), \delta: 3.54$ (tdd, $1 \mathrm{H}, J$ $\left.=10.7,5.5,3.6 \mathrm{~Hz}, \mathrm{C} 4 \mathrm{a}^{\prime}-\mathrm{H}\right), 3.10\left(\mathrm{ddd}, 1 \mathrm{H}, J=15.3,10.9,5.9 \mathrm{~Hz}, \mathrm{C} 3{ }^{\prime}-\mathrm{H}_{\mathrm{c}}\right), 2.92(\mathrm{~s}, 1 \mathrm{H}$, C3a-H), $2.87\left(\mathrm{dd}, 1 \mathrm{H}, J=15.3,7.6 \mathrm{~Hz}, \mathrm{C}^{\prime}-\mathrm{H}_{\mathrm{t}}\right), 2.85(\mathrm{~d}, 1 \mathrm{H}, J=12.8 \mathrm{~Hz}, \mathrm{C} 1-\mathrm{H}), 2.68(\mathrm{~m}$, 1H, C2-H), 2.68 (m, 1H, C11'-H), 2.66 (m, 1H, C11'-H), 2.65 (m, 1H, C5a-H), 2.64 (m, 1H, $\left.\mathrm{C}^{\prime}-\mathrm{H}_{\mathrm{c}}\right), 2.47$ (ddd, $\left.1 \mathrm{H}, J=15.9,11.8,6.4 \mathrm{~Hz}, \mathrm{C}^{\prime}-\mathrm{H}_{\mathrm{t}}\right), 2.38(\mathrm{dt}, 1 \mathrm{H}, J=14.4,4.2 \mathrm{~Hz}, \mathrm{C} 8-$ $\left.\mathrm{H}_{\mathrm{t}}\right), 2.26(\mathrm{dq}, 1 \mathrm{H}, J=14.3,7.3 \mathrm{~Hz}, \mathrm{C} 11-\mathrm{H}), 2.17\left(\mathrm{dt}, 1 \mathrm{H}, J=10.7,5.7 \mathrm{~Hz}, \mathrm{C} 4^{\prime}-\mathrm{H}_{\mathrm{c}}\right), 2.14(\mathrm{td}$, $\left.1 \mathrm{H}, J=11.9,7.6 \mathrm{~Hz}, \mathrm{C} 4-\mathrm{H}_{\mathrm{c}}\right), 2.05$ (dq, 1H, J =14.3, 7.3 Hz, C11-H'), $1.90\left(\mathrm{~m}, 1 \mathrm{H}, \mathrm{C} 4-\mathrm{H}_{\mathrm{t}}\right)$, $1.90\left(\mathrm{~m}, 1 \mathrm{H}, \mathrm{C} 8-\mathrm{H}_{\mathrm{c}}\right), 1.81\left(\mathrm{tdd}, 1 \mathrm{H}, J=13.6,5.5,4.7 \mathrm{~Hz}, \mathrm{C} 6-\mathrm{H}_{\mathrm{c}}\right), 1.72(\mathrm{~m}, 1 \mathrm{H}, \mathrm{C} 3-\mathrm{H}), 1.71$ $\left(\mathrm{m}, 1 \mathrm{H}, \mathrm{C}^{\prime}-\mathrm{H}_{\mathrm{t}}\right), 1.70\left(\mathrm{~m}, 1 \mathrm{H}, \mathrm{C}^{\prime}-\mathrm{H}_{\mathrm{t}}\right), 1.67(\mathrm{~m}, 1 \mathrm{H}, \mathrm{C} 9-\mathrm{H}), 1.63\left(\mathrm{~m}, 1 \mathrm{H}, \mathrm{C}^{\prime}-\mathrm{H}_{\mathrm{c}}\right), 1.56(\mathrm{td}, J$ $\left.=11.7,3.6 \mathrm{~Hz}, 1 \mathrm{H}, \mathrm{C} 5-\mathrm{H}_{\mathrm{t}}\right), 1.51\left(\mathrm{dddd}, J=13.5,5.2,3.2,1.9,1 \mathrm{H}, \mathrm{C} 6-\mathrm{H}_{\mathrm{t}}\right), 1.42(\mathrm{~m}, 1 \mathrm{H}, \mathrm{C} 7-$ $\left.\mathrm{H}_{\mathrm{c}}\right), 1.41\left(\mathrm{~m}, 1 \mathrm{H}, \mathrm{C}^{\prime}-\mathrm{H}_{\mathrm{c}}\right), 1.34\left(\mathrm{t}, 3 \mathrm{H}, J=7.5 \mathrm{~Hz}, \mathrm{C} 12^{\prime}-\mathrm{H}\right), 1.25\left(\mathrm{~m}, 1 \mathrm{H}, \mathrm{C} 9-\mathrm{H}^{\prime}\right), 1.24(\mathrm{~m}$, $\left.1 \mathrm{H}, \mathrm{C} 7-\mathrm{H}_{\mathrm{t}}\right), 1.14(\mathrm{t}, 3 \mathrm{H}, J=7.3 \mathrm{~Hz}, \mathrm{C} 12-\mathrm{H}), 1.07$ (t, 3H, J=7.3 Hz, C10-H), 1.06 (m, 1H, $\left.\mathrm{C} 5-\mathrm{H}_{\mathrm{c}}\right), 1.03\left(\mathrm{~d}, 1 \mathrm{H}, J=7.0 \mathrm{~Hz}, \mathrm{C} 10^{\prime}-\mathrm{H}\right), 0.96\left(\mathrm{tdd}, 1 \mathrm{H}, J=12.8,10.7,2.4 \mathrm{~Hz}, \mathrm{C}^{\prime}-\mathrm{H}_{\mathrm{t}}\right) .{ }^{13} \mathrm{C}$ NMR (125.8 MHz, $\left.\mathrm{C}_{6} \mathrm{D}_{6}, 23^{\circ} \mathrm{C}\right), \delta: 140.5$ (C8a), 128 (C2a'), 123.2 (C1'), 117.4 (C7a'), 114.8 (C8b), 111.2 (C2'), 83.6 (C3b), 62.0 (C3a), 58.8 (C5a), 55.5 (C4a'), 51.9 (C1), 50.1 (C3), 40.1 (C2), 38.2 (C4), 37.5 (C4'), 30.5 (C5'), 28.6 (C3'), 28.0 (C5), 27.7 (C6), 24.9 (C8), 23.3 (C6'), 22.9 (C9), 21.3 (C7'), 20.6 (C7), 19.9 (C11), 19.3 (C11'), 17.3 (C12'), 14.9 (C12), 14.7 (C10'), 13.6 (C10). HRMS (ESI): $m / z$ calcd for $\mathrm{C}_{30} \mathrm{H}_{44} \mathrm{~N}_{2}[\mathrm{M}+\mathrm{H}]^{+}$: 433.3577 ; Found: 433.3566. TLC (silica gel pre-treated with $\mathrm{Et}_{3} \mathrm{~N}, 1.5 \% \mathrm{Et}_{3} \mathrm{~N}, 2.5 \% \mathrm{EtOAc}$-hexanes), $R_{\mathrm{f}}: 0.27$ (UV, anis).

\subsubsection{Bromophenylketone 29}

A sample of alcohol 21 (9.6 mg, $41.2 \mu \mathrm{mol}, 1$ equiv) was dried by concentration from anhydrous benzene $(3 \times 500 \mu \mathrm{L})$. The residue was dissolved in benzene $(1.0 \mathrm{~mL})$ and was purged by a stream of argon for $3 \mathrm{~min}$. A solution of TFA $(3.4 \mu \mathrm{L}, 45.3 \mu \mathrm{mol}, 1.10$ equiv) in benzene $(25.0 \mu \mathrm{L})$ was added drop-wise via syringe. The pale yellow mixture became 
intense yellow immediately upon addition of TFA and faded to a clear tan color solution within $2 \mathrm{~min}$. The reaction mixture was mixed and maintained at ambient temperature for $4.5 \mathrm{~h}$ under strictly inert atmosphere to allow complete conversion of the myrmicarin $215 \mathrm{~B}$ (4) to the iminium ion 26. A single portion of resin-bound BEMP (187 mg, $2.2 \mu \mathrm{mol} / \mathrm{mg}$ on 200-400 mesh polystyrene resin, 10.0 equiv) was added under an inert atmosphere (glovebox, nitrogen atmosphere) to the solution of the iminium salt $\mathbf{2 6}$ and the resulting pale yellow suspension was stirred under strictly inert conditions. After $30 \mathrm{~min}$, the yellow suspension was filtered through a cotton plug into a recovery flask and the transfer was completed using additional benzene $(3 \times 450 \mu \mathrm{L})$ as a rinse. The flask was sealed under nitrogen and removed from the glove-box. The pale yellow solution was concentrated partially under reduced pressure (to $\sim 750 \mu \mathrm{L}$ ). Diisopropylethyamine $(89.7 \mu \mathrm{L}, 515 \mu \mathrm{mol}$, 12.5 equiv) was added via syringe at ambient temperature, followed by 4-bromobenzoyl chloride (11.3 mg, $51.5 \mu \mathrm{mol}, 1.25$ equiv) as a solid in a single portion and the flask was immediately resealed and flushed with argon. The resulting intense yellow, slightly opaque mixture was vigorously stirred at ambient temperature. After $30 \mathrm{~min}$, diisopropylamine (150 $\mu \mathrm{L}, 1.07 \mathrm{mmol}, 26.1$ equiv) was introduced via syringe to quench the excess acid chloride. After $5 \mathrm{~min}$, the suspension was concentrated under reduced pressure to give the crude product as a bright yellow semi-solid. Purification of the residue by column chromatography on silica gel $\left(5 \% \mathrm{Et}_{3} \mathrm{~N}, 5 \%\right.$ EtOAc-hexanes, diameter $1.5 \mathrm{~cm}$, height $\left.15 \mathrm{~cm}\right)$ afforded the benzoylated derivative 29 as a bright yellow oil $(8.4 \mathrm{mg}, 67 \%) .{ }^{1} \mathrm{H}$ NMR $\left(500 \mathrm{MHz}, \mathrm{C}_{6} \mathrm{D}_{6}\right.$, $\left.23{ }^{\circ} \mathrm{C}\right), \delta: 7.67\left(\mathrm{~d}, 2 \mathrm{H}, J=8.2 \mathrm{~Hz}, \mathrm{C} 15-\mathrm{H}, \mathrm{C} 15^{\prime}-\mathrm{H}\right), 7.29$ (d, 2H, $J=8.2 \mathrm{~Hz}, \mathrm{C} 16-\mathrm{H}, \mathrm{C} 16^{\prime}-$ H), 3.48 (tdd, $1 \mathrm{H}, J=10.7,5.0,3.7 \mathrm{~Hz}, \mathrm{C} 4 \mathrm{a}$ '-H), 3.16 (dq, $1 \mathrm{H}, J=14.0,7.3 \mathrm{~Hz}, \mathrm{C} 11-\mathrm{H}$ ), $2.80(\mathrm{~m}, 1 \mathrm{H}, \mathrm{C} 5 \mathrm{a}-\mathrm{H}), 2.78\left(\mathrm{~m}, 1 \mathrm{H}, \mathrm{C}^{\prime}-\mathrm{H}_{\mathrm{c}}\right), 2.65\left(\mathrm{~m}, 1 \mathrm{H}, \mathrm{C}^{\prime}-\mathrm{H}_{\mathrm{t}}\right), 2.62\left(\mathrm{~m}, 1 \mathrm{H}, \mathrm{C}^{\prime}-\mathrm{H}_{\mathrm{c}}\right)$, $2.59\left(\mathrm{~m}, 2 \mathrm{H}, \mathrm{C} 11^{\prime}-\mathrm{H}\right), 2.48(\mathrm{~m}, 1 \mathrm{H}, \mathrm{C} 3-\mathrm{H}), 2.44\left(\mathrm{~m}, 1 \mathrm{H}, \mathrm{C}^{\prime}-\mathrm{H}_{\mathrm{c}}\right), 2.38(\mathrm{dt}, 1 \mathrm{H}, J=13.8,3.3$ $\left.\mathrm{Hz}, \mathrm{C} 7-\mathrm{H}_{\mathrm{t}}\right), 2.25\left(\mathrm{~m}, 1 \mathrm{H}, \mathrm{C} 11-\mathrm{H}^{\prime}\right), 2.24\left(\mathrm{td}, 1 \mathrm{H}, J=13.8,2.9 \mathrm{~Hz}, \mathrm{C} 7-\mathrm{H}_{\mathrm{c}}\right), 2.20(\mathrm{~m}, 1 \mathrm{H}, \mathrm{C} 2-$ H), $2.15\left(\mathrm{~m}, 1 \mathrm{H}, \mathrm{C} 5-\mathrm{H}_{\mathrm{t}}\right), 2.13\left(\mathrm{~m}, 1 \mathrm{H}, \mathrm{C}^{\prime}-\mathrm{H}_{\mathrm{c}}\right), 1.69\left(\mathrm{~m}, 1 \mathrm{H}, \mathrm{C6}^{\prime}-\mathrm{H}_{\mathrm{t}}\right), 1.65\left(\mathrm{~m}, 1 \mathrm{H}, \mathrm{C} 4-\mathrm{H}_{\mathrm{c}}\right)$, $1.63\left(\mathrm{~m}, 1 \mathrm{H}, \mathrm{C}^{\prime}-\mathrm{H}_{\mathrm{t}}\right), 1.61\left(\mathrm{~m}, 1 \mathrm{H}, \mathrm{C} 4-\mathrm{H}_{\mathrm{t}}\right), 1.56\left(\mathrm{~m}, 1 \mathrm{H}, \mathrm{C}^{\prime}-\mathrm{H}_{\mathrm{c}}\right), 1.52\left(\mathrm{~m}, 1 \mathrm{H}, \mathrm{C} 5-\mathrm{H}_{\mathrm{c}}\right), 1.44$ $(\mathrm{m}, 1 \mathrm{H}, \mathrm{C} 9-\mathrm{H}), 1.43\left(\mathrm{~m}, 1 \mathrm{H}, \mathrm{C} 6-\mathrm{H}_{\mathrm{c}}\right), 1.38\left(\mathrm{~m}, 1 \mathrm{H}, \mathrm{C}^{\prime}-\mathrm{H}_{\mathrm{c}}\right), 1.32\left(\mathrm{t}, 3 \mathrm{H}, J=7.6 \mathrm{~Hz}, \mathrm{C} 12^{\prime}-\mathrm{H}\right)$, 1.23 (m, 1H, C9-H'), 1.19 (t, 3H, $J=7.3 \mathrm{~Hz}, \mathrm{C} 12-\mathrm{H}), 0.95$ (d, 3H, $\left.J=6.7 \mathrm{~Hz}, \mathrm{C} 10^{\prime}-\mathrm{H}\right), 0.93$ (t, $3 \mathrm{H}, J=7.6 \mathrm{~Hz}, \mathrm{C} 10-\mathrm{H}), 0.89$ (tdd, $\left.1 \mathrm{H}, J=12.6,10.4,2.2 \mathrm{~Hz}, \mathrm{C}^{\prime}-\mathrm{H}_{\mathrm{t}}\right), 0.82$ (dtd, $1 \mathrm{H}, J=$ $\left.13.8,11.9,2.9 \mathrm{~Hz}, \mathrm{C} 6-\mathrm{H}_{\mathrm{t}}\right) .{ }^{13} \mathrm{C} \mathrm{NMR}\left(125.8 \mathrm{MHz}, \mathrm{C}_{6} \mathrm{D}_{6}, 23{ }^{\circ} \mathrm{C}\right), \delta: 190.4(\mathrm{C} 13), 162.6$ (C3a), 162.6 (C8a), 141.8 (C14), 136.6 (C8b), 131.8 (C15), 131.4 (C16), 128 (C2a'), 125.2 (C17), 122.0 (C1'), 117.5 (C7a'), 113.6 (C2'), 104.2 (C8), 86.9 (C3b), 55.6 (C4a'), 54.6 (C5a), 49.4 (C2), 48.5 (C1), 45.1 (C3), 41.0 (C4), 37.3 (C4'), 36.7 (C5), 30.4 (C6), 30.1 (C5'), 28.8 (C7), 27.5 (3'), 23.2 (C6'), 21.2 (C7'), 20.9 (C11), 20.8 (C9), 19.0 (C11'), 17.4 (C12'), $16.3\left(\mathrm{C} 10^{\prime}\right), 14.8(\mathrm{C} 12), 13.6(\mathrm{C} 10)$. HRMS (ESI): $\mathrm{m} / z$ calcd for $\mathrm{C}_{37} \mathrm{H}_{45} \mathrm{BrN}_{2} \mathrm{O}$ [M $+\mathrm{H}]^{+}$: 613.2788; Found: 613.2771. TLC (silica gel, 20\% EtOAc-hexanes), $R_{\mathrm{f}}: 0.41$ (UV, ninhydrin).

\section{Acknowledgments}

M.M. is a Dale F. and Betty Ann Frey Damon Runyon Scholar supported by the Damon Runyon Cancer Research Foundation (DRS-39-04). M.M. is a Firmenich Assistant Professor of Chemistry. A.E.O. acknowledges a Novartis Graduate Fellowship. We thank Professor Robert G. Griffin and Dr. Tony Bielecki for use of a high field instrument at the MIT-Harvard Center for Magnetic Resonance (EB-002026). The MIT-DCIF is supported in part by NSF (CHE-9808061 and DBI-9729592) and NIH (1S10RR13886-01). We are grateful for the financial support by the American Chemical Society PRF (40631G1), MIT, Amgen Inc., and NIH-NIGMS (GM074825).

\section{References}

1. (a) Francke W, Schröder F, Walter F, Sinnwell V, Baumann H, Kaib M. Liebigs Ann 1995:965977. (b) Schröder F, Franke S, Francke W. Tetrahedron 1996;52:13539-13546. (c) Schröder F, Sinnwell V, Baumann H, Kaib M. J. Chem. Soc. Chem. Commun 1996:2139-2130. (d) Schröder F, Sinnwell V, Baumann H, Kaib M, Francke W. Angew. Chem. Int., Ed. Engl 1997;36:77-80. 
2. Schröder F, Francke W. Tetrahedron 1998;54:5259-5264.

3. The C2-C8 olefin geometry of this putative intermediate (i.e. 10) is not known at this time as we have not directly observed this intermediate spectroscopically.

4. Upon formation of the first carbon-carbon bond the numbering used for all dimeric compounds is consistent with the numbering system for myrmicarin 430A (1) (see ref. 1c).

5. Movassaghi M, Ondrus AE. Org. Lett 2005;7:4423-4426. [PubMed: 16178549]

6. For a previous total syntheses of $(R)-(+)$ - myrmicarin 217 (6), see: Sayah B, Pelloux-Léon N, Vallée Y. J. Org. Chem 2000;65:2824-2826. [PubMed: 10808465] For a previous total synthesis of ( \pm )myrmicarin $217(6)$, see reference ${ }^{2}$. For a formal synthesis of $(S)-(-)$ - myrmicarin $217(6)$, see: Settambolo R, Guazzelli G, Lazzaroni R. Tetrahedron: Asymmetry 2003;14:1447-1449. For a previous enantioselective synthesis of myrmicarin 215 as a mixture of alkene isomers, see: Sayah B, Pelloux-Léon N, Milet A, Pardillos-Guindet J, Vallée Y. J. Org. Chem 2001;66:2522-2525. [PubMed: 11281803]

7. Movassaghi M, Ondrus AE. J. Org. Chem 2005;70:8638-8641. [PubMed: 16209629]

8. For recent reviews on transition metal catalyzed C-N bond formation, see: (a) Wolfe JP, Wagaw S, Marcoux J-F, Buchwald SL. Acc. Chem. Res 1998;31:805-818. (b) Hartwig, J. F. ., 852-860. (c) Hartwig, J. F. Angew. Chem. Int. Ed. 37, 2046-2067. (d) Yang, B. H.; Buchwald, S. L. J. Organomet. Chem 576-146. (e) Muci AR, Buchwald SL. Top. Curr. Chem 2002;219:131-209. (f) Hartwig, JF. Handbook of Organopalladium Chemistry. for Organic Synthesis For palladiumcatalyzed N-vinylation of lithiated azoles, see: (g) Lebedev AY, Izmer VV, Kazyul'kin DN, Beletskaya IP, Voskoboynikov AZ. Org. Lett 2002;4:623-626. [PubMed: 11843607] For recent reports on palladium-catalyzed N-vinylation, see: (h) Wallace DJ, Klauber DJ, Chen C.-y. Volante RP. Org. Lett 2003;5:4749-4752. [PubMed: 14627431] and (i) Klapars A, Campos KR, Chen C.-y. Volante RP. Org. Lett 2005;7:1185-1188. [PubMed: 15760170]

9. Rainka MP, Aye Y, Buchwald SL. Proc. Nat. Acad. Sci., USA 2004;101:5821-5823. [PubMed: 15067136]

10. For recent reports on $\mathrm{CuH}$-catalyzed asymmetric conjugate reduction, see: (a) Lipshutz $\mathrm{BH}$, Servesko JM. Angew. Chem., Int. Ed 2003;42:4789-4792. (b) Hughes G, Kimura M, Buchwald SL. J. Am. Chem. Soc 2003;126:11253-11258. [PubMed: 16220945] and references cited therein. For related references, see: (c) Mahoney WS, Stryker JM. J. Am. Chem. Soc 1989;111:88188823. (d) Mori A, Fujita A, Kajiro H, Nishihara Y, Hiyama T. Tetrahedron 1999;55:4573-4582.

11. Tsuji T, Watanabe Y, Mukaiyama T. Chem. Lett 1979:481-482.

12. Owing to their acid sensitivity, none of the tricyclic myrmicarins could be efficiently purified by silica gel chromatography due to poor mass recovery. While spectroscopically pure samples of myrmicarins $215 \mathrm{~A}, 215 \mathrm{~B}$, and 217 could be obtained without purification, all of the tricyclic myrmicarins could be subject to alumina gel chromatography without significant loss of material.

13. While the exact position of protonation was unclear, the resonances corresponding to the C8-C9 vinyl groups of two major pyrrole-ring protonated compounds were visible.

14. Chiang Y, Hinman RL, Theodoropulos S, Whipple EB. Tetrahedron 1967;23:745-759.

15. A stable cyanide-adduct formation was not observed $\left({ }^{1} \mathrm{H}\right.$ NMR, TLC) under a variety of reaction conditions.

16. While an azafulvenium ion is not observed spectroscopically, a potential equilibration between iminium ion $\mathbf{1 3}$ and azafulvenium ion $\mathbf{1 1}$ (Scheme 3 ) followed by rapid reduction may provide $\mathbf{2 5 .}$ Alternatively C1-delivery of a hydride with concomitant displacement of a pyrroloindolizine would not require equilibration to the azafulvenium ion.

17. For reviews on the chemistry of pyrroles, see: (a) Schofield, K. Hetero-Aromatic Nitrogen Compounds. Butterworths; London: 1967. (b) Patterson JM. Synthesis 1976:281-304. (c) Jones, A., editor. Pyrroles. Wiley; New York: 1990.

18. The formation of enamine $\mathbf{2 8}$ is consistent with hydrogenation of $\mathrm{C} 3 \mathrm{a}-\mathrm{C} 8 \mathrm{~b}$ alkene followed by tautomerization to the tetrasubstituted $\mathrm{C} 8 \mathrm{a}$-enamine.

19. Hydrogenation of this enamine under forcing conditions $\left(160 \mathrm{psi}_{2}, 23{ }^{\circ} \mathrm{C}, 60 \mathrm{~h}\right)$ did provide further reduction of the enamine to the corresponding amine as a single diastereomer with similar chemical lability to $\mathbf{2 8}$. 
20. The designations $\mathrm{C} 4-\mathrm{H}_{\mathrm{c}}$ and $\mathrm{C} 4-\mathrm{H}_{\mathrm{t}}$ refer to the protons cis and trans to the $\mathrm{C} 4 \mathrm{a}$ methine, respectively.

21. (a) While equilibrium of $\mathbf{3 0}$ and $\mathbf{3 1}$ is neither supported by spectroscopic data nor by enthalpic considerations, the presence of this equilibrium cannot be ruled out at this time. (b) Alternative cycloaddition type processes for the direct union of $\mathbf{4}$ and $\mathbf{1 0}$ to provide iminium ion $\mathbf{3 1}$ have been considered, and as with other possibilities necessarily await further experimental data.

22. Still WC, Kahn M, Mitra A. J. Org. Chem 1978;43:2923-2925.

23. Pangborn AB, Giardello MA, Grubbs RH, Rosen RK, Timmers FJ. Organometallics 1996;15:1518-1520.

24. While the critical spin system (C1-C3) was conclusively assigned, the two overlapping pyrroloindolizine spin systems of hexacycle $24\left(\mathrm{C} 4-\mathrm{C} 8\right.$ and $\left.\mathrm{C}^{\prime}-\mathrm{C}^{\prime}\right)$ are identified but not assigned. 


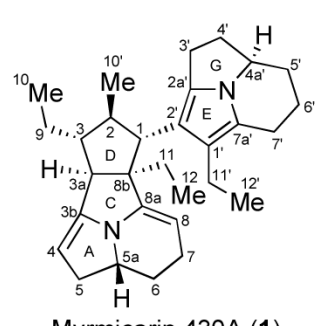

Myrmicarin 430A (1)
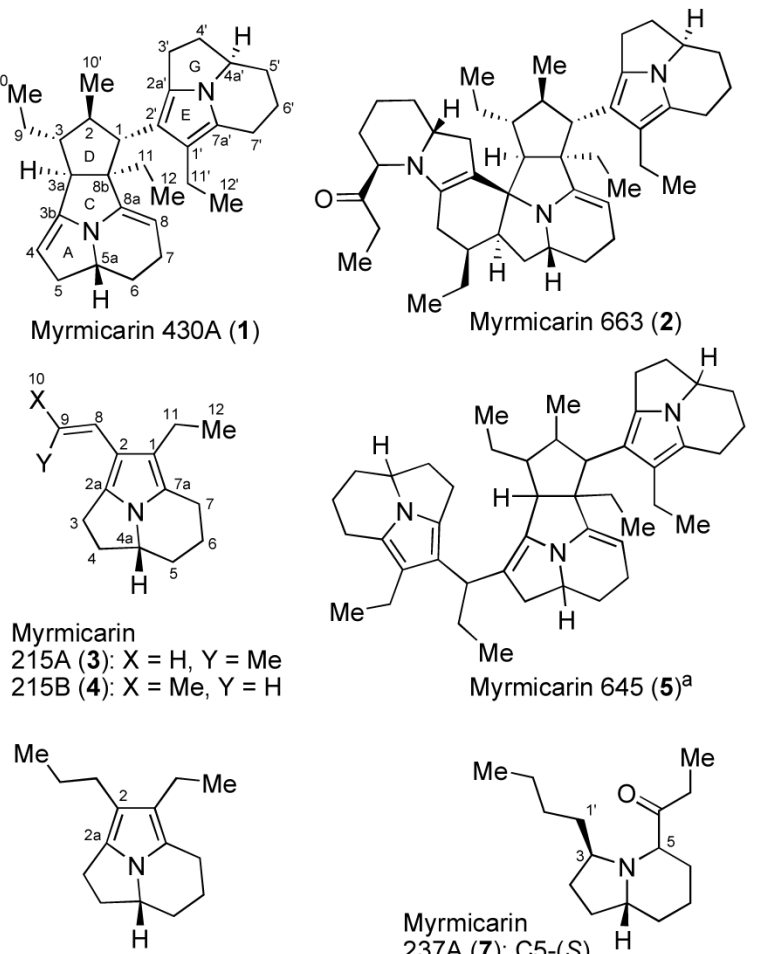

Myrmicarin 217 (6)

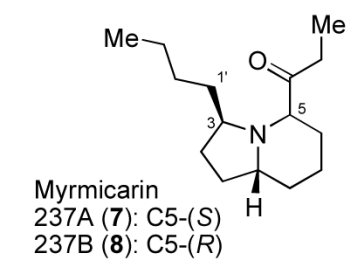

Figure 1.

Representative members of the myrmicarin family of alkaloids. ${ }^{\text {a}}$ The relative stereochemistry of $\mathbf{5}$ is unknown; see reference $1 \mathrm{~d}$. 
A. $\mathrm{HMBC}$ Correlations $\left({ }^{1} \mathrm{H} \rightarrow{ }^{13} \mathrm{C}\right)$

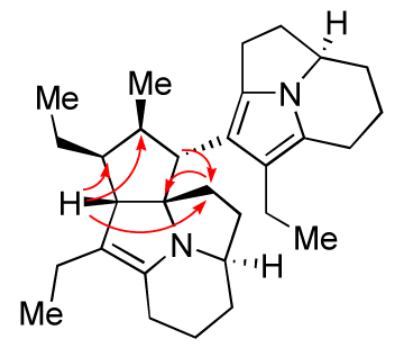

28
B. NOESY Correlations

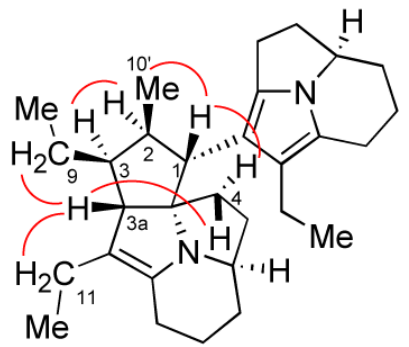

28

Figure 2.

Key HMBC $\left({ }^{1} \mathrm{H} \rightarrow{ }^{13} \mathrm{C}\right)$ and NOESY correlations for the enamine 28. 


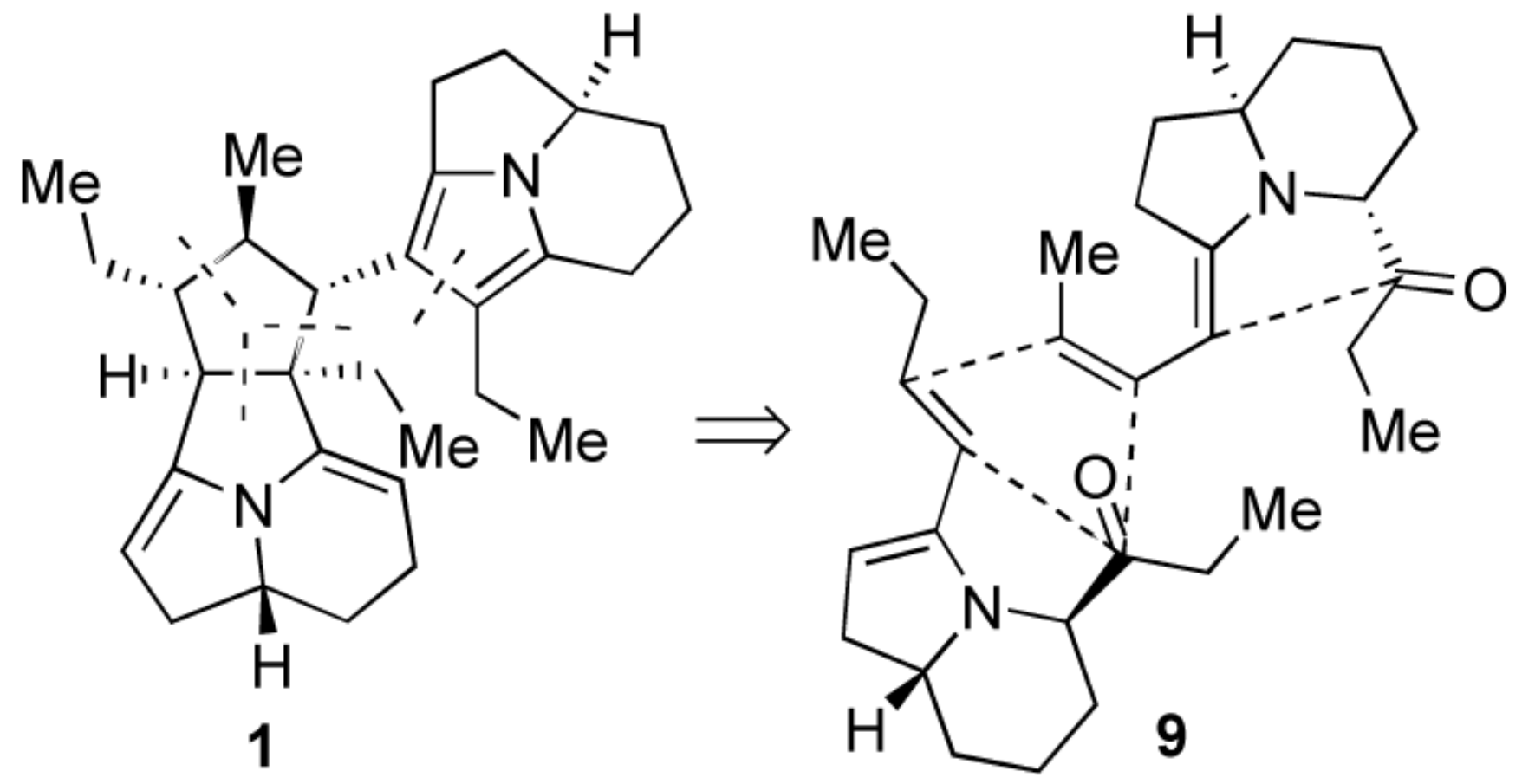

Scheme 1.

Francke's proposed dimerization of bicyclic diene 9 to give myrmicarin 430A (1). 


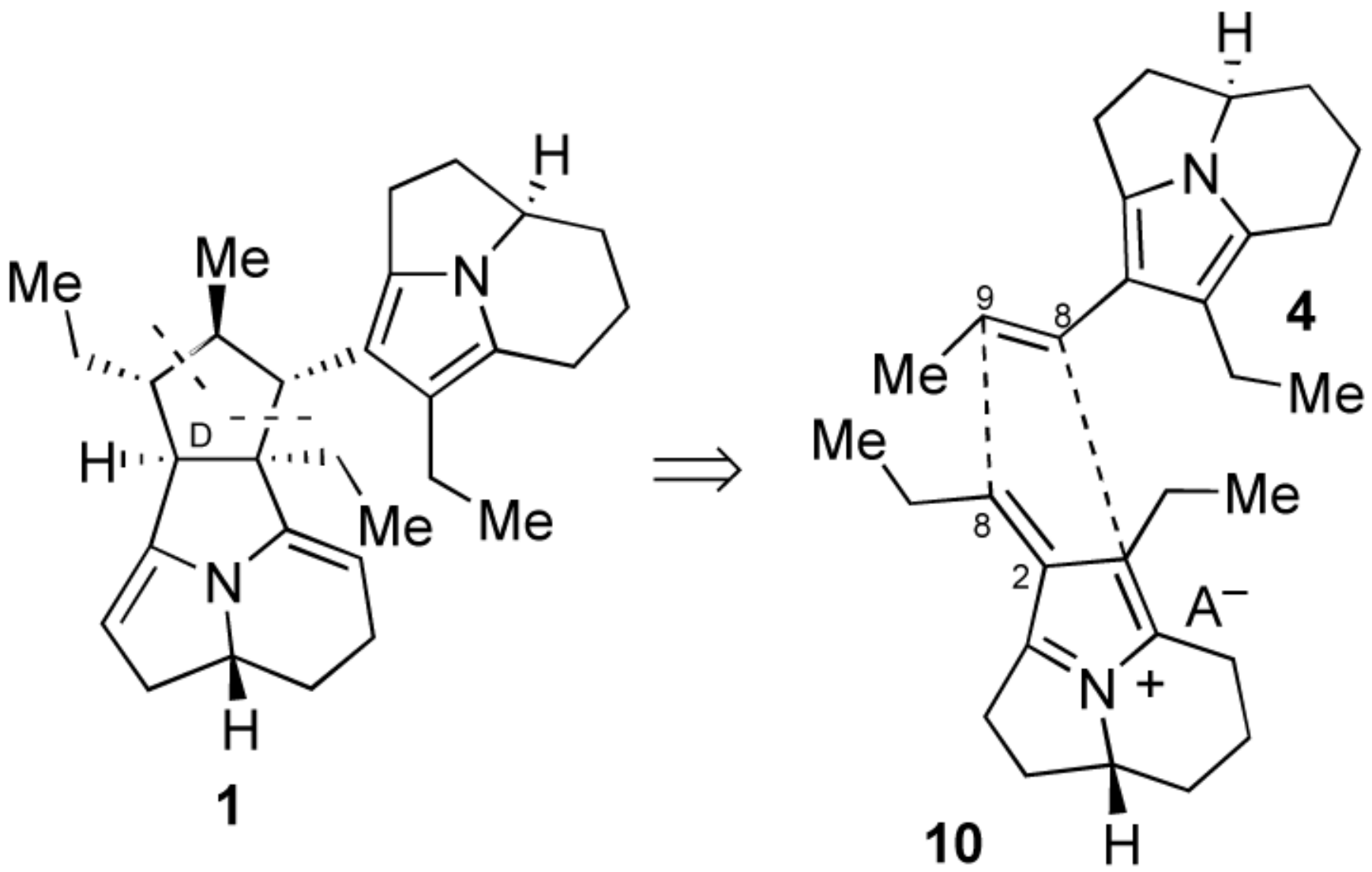

Scheme 2.

Our proposed potential biomimetic dimerization of pyrroloindolizines to give of myrmicarin 430A (1). 

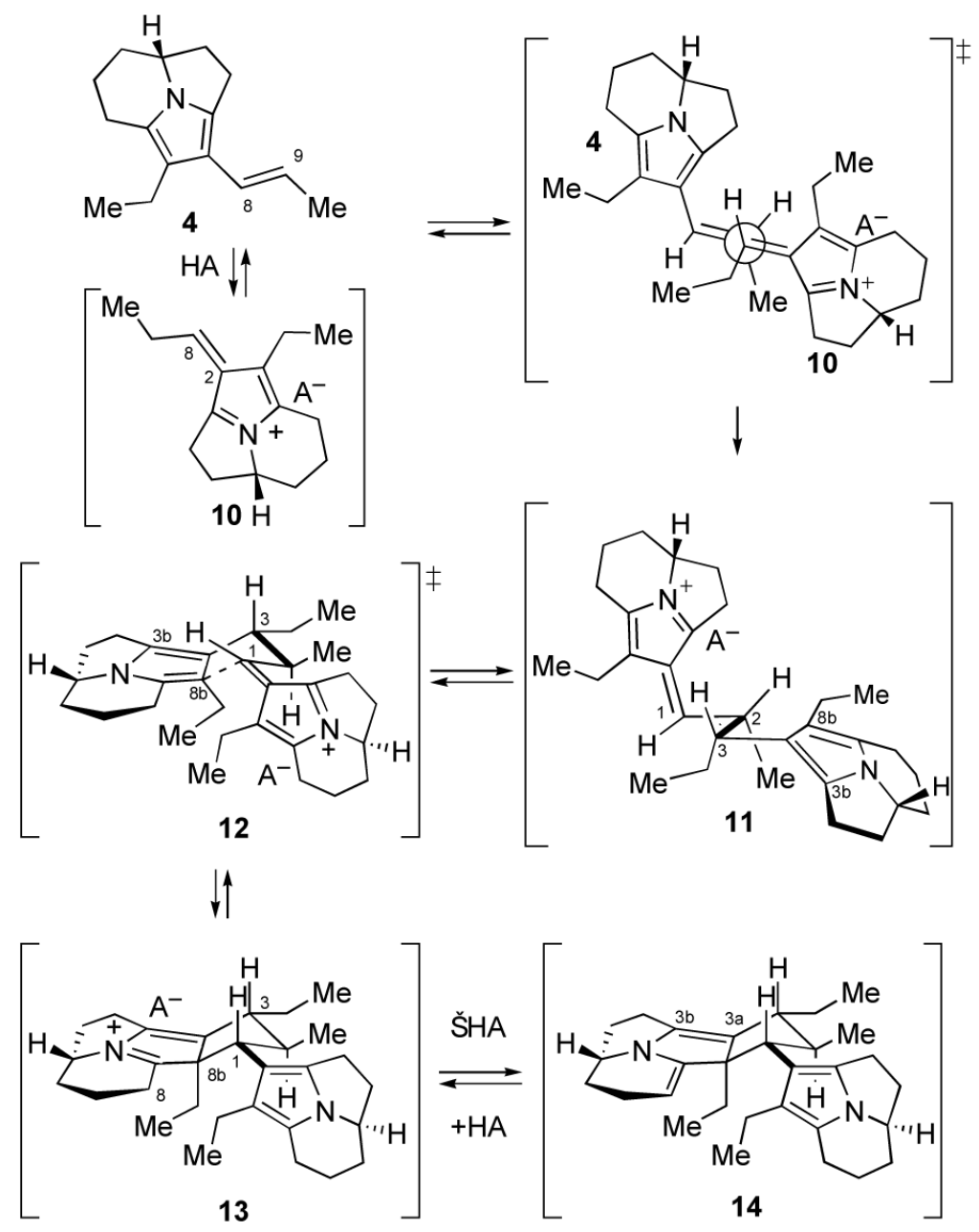

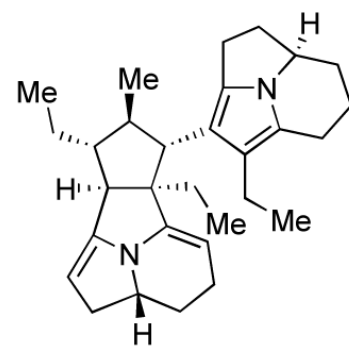

Myrmicarin 430A (1)

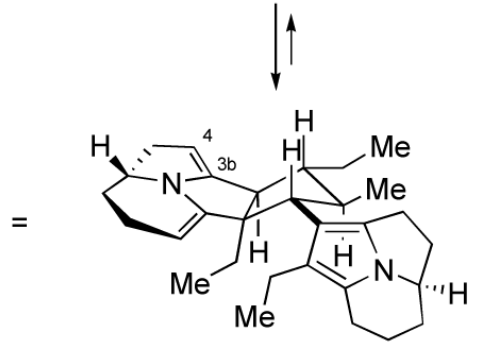

Myrmicarin 430A (1)

Scheme 3.

Our proposed dimerization of myrmicarin 215B (4) to give 1. 


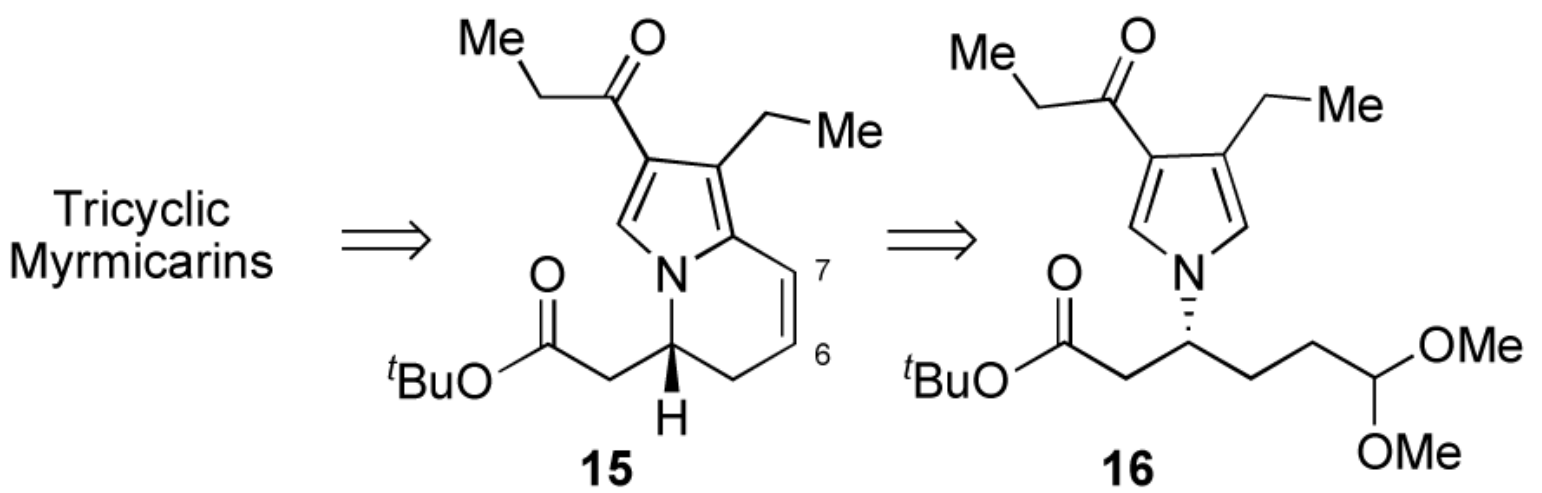<smiles>C=CCc1c[nH]cc1C(=O)CC</smiles>

Scheme 4.

Synthesis of key bicyclic intermediate $\mathbf{1 5}$. 


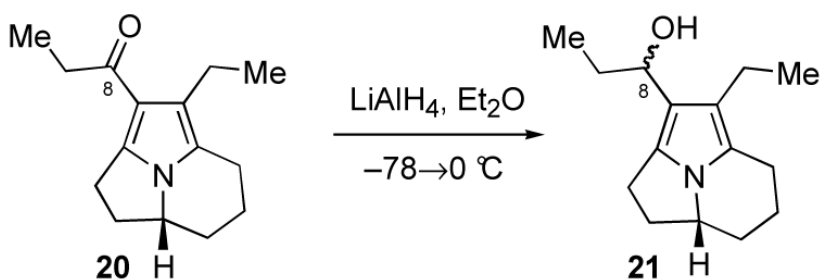

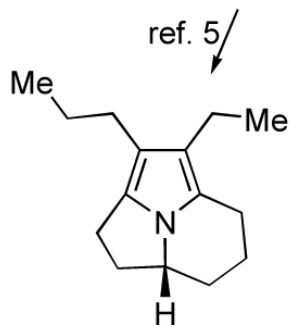

Myrmicarin 217 (6)

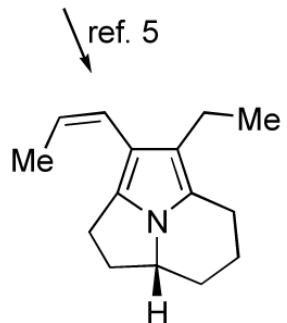

Myrmicarin 215A (3)

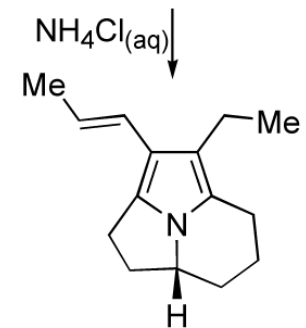

Myrmicarin 215B (4)

Scheme 5.

Enantioselective synthesis of the tricyclic myrmicarin alkaloids. 

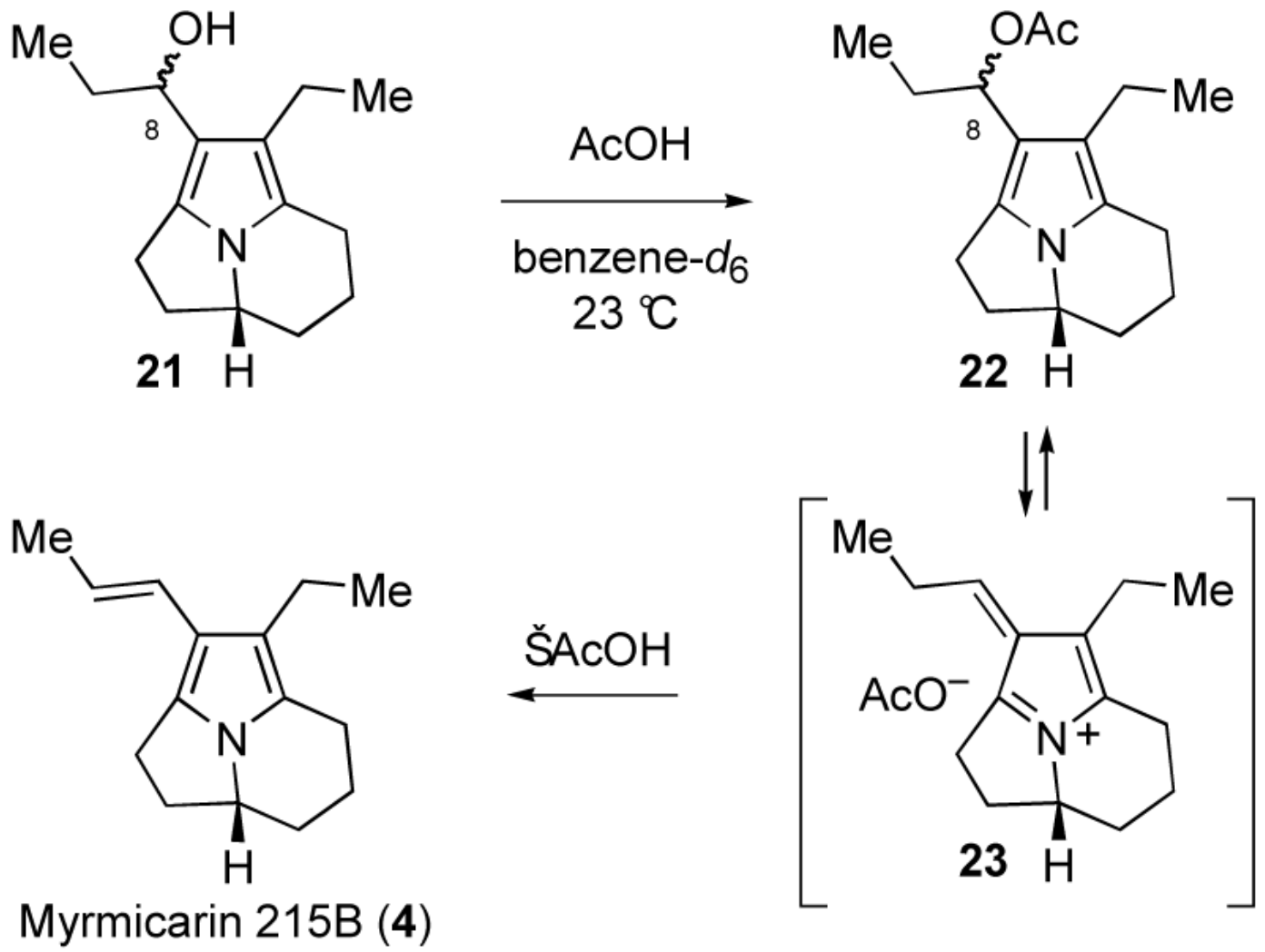

Scheme 6.

Acetic acid catalyzed dehydration of alcohol 21 to myrmicarin 215B (4). 

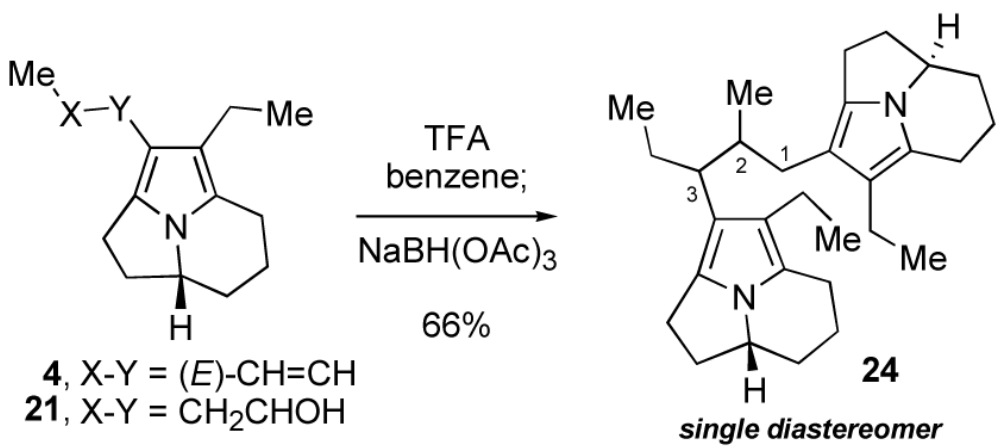

Scheme 7.

Acid promoted dimerization of myrmicarin 215B (4) followed by immediate reduction to provide the first isolable dimeric product $\mathbf{2 4}$. The $\mathrm{C} 2$ - and $\mathrm{C} 3$-stereochemistry was later assigned; see below. 

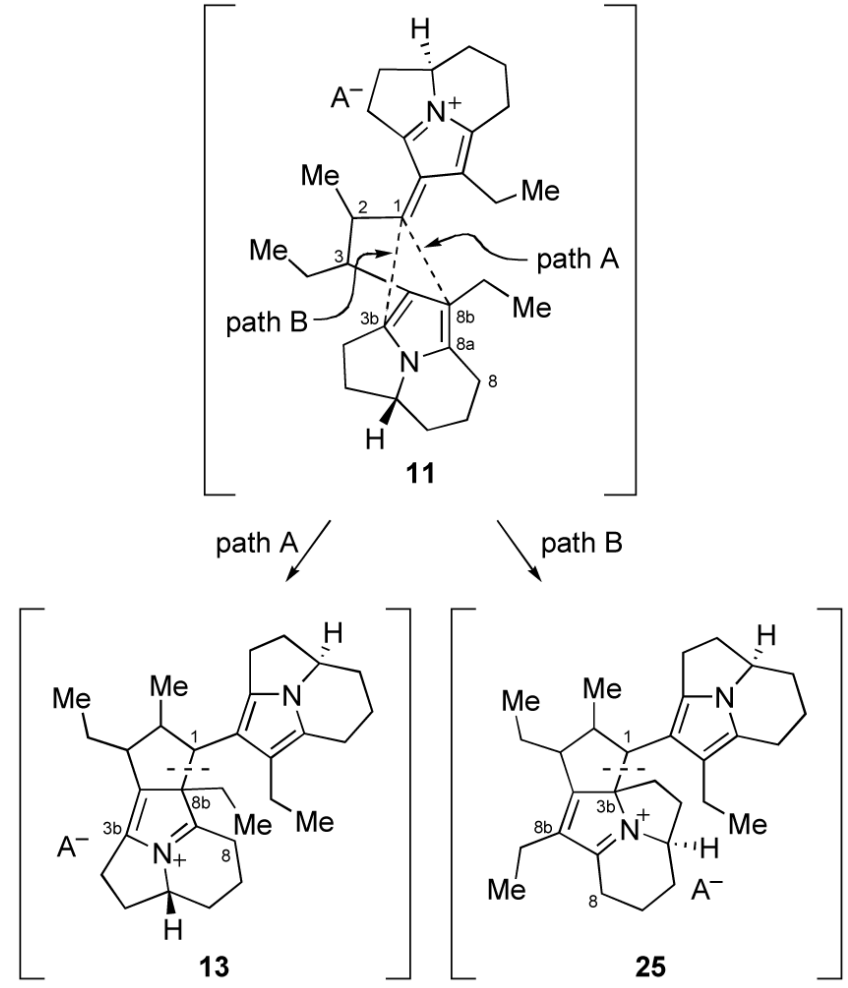

Scheme 8.

Two possible modes of intramolecular azafulvenium ion trapping leading to isomeric heptacyclic iminium ions $\mathbf{1 3}$ and 25. 


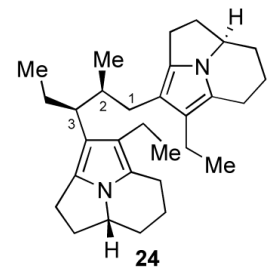

single diastereomer

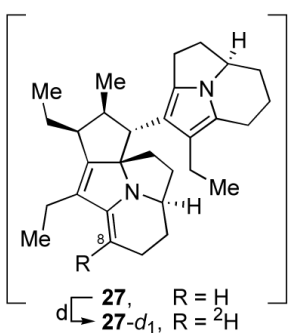

e

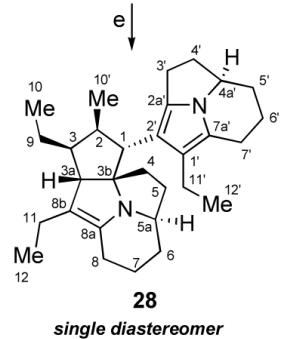

Me

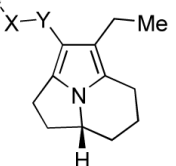

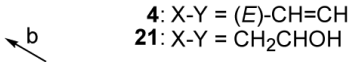

a

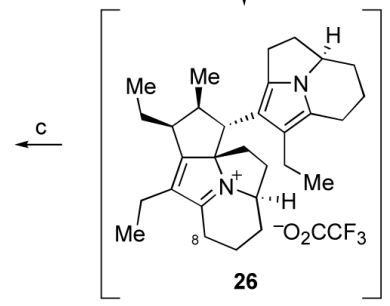

$\searrow$

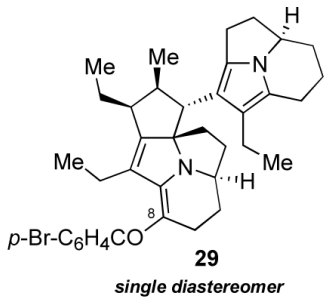

Scheme 9.

TFA promoted dimerization of myrmicarin 215B (4) and related derivtives. For stereochemical assignment please see below. (a) TFA, benzene- $d_{6}, 23{ }^{\circ} \mathrm{C}, 3 \mathrm{~h}, \square 90 \%$. (b) $\mathrm{NaBH}(\mathrm{OAc})_{3}, \mathrm{MeCN}-d_{3}$, benzene- $d_{6}, 23{ }^{\circ} \mathrm{C}, 3.5 \mathrm{~h}, 68 \%$ from 21. (c) resin bound-BEMP, benzene- $d_{6}, 23{ }^{\circ} \mathrm{C}, 30 \mathrm{~min}$. (d) methanol- $d_{4}\left(\sim 15\right.$ equiv), benzene- $d_{6}, 23{ }^{\circ} \mathrm{C}, 1.5 \mathrm{~h}$, complete $\mathrm{C} 8$ deuterium incorporation. (e) $\mathrm{Pd} / \mathrm{C}, \mathrm{H}_{2}, 87 \%$ from 21. (f) $p$ - $\mathrm{BrPhCOCl}, 30 \mathrm{~min} ;{ }^{i} \mathrm{Pr}_{2} \mathrm{NH}$, $67 \%$ from 21. 

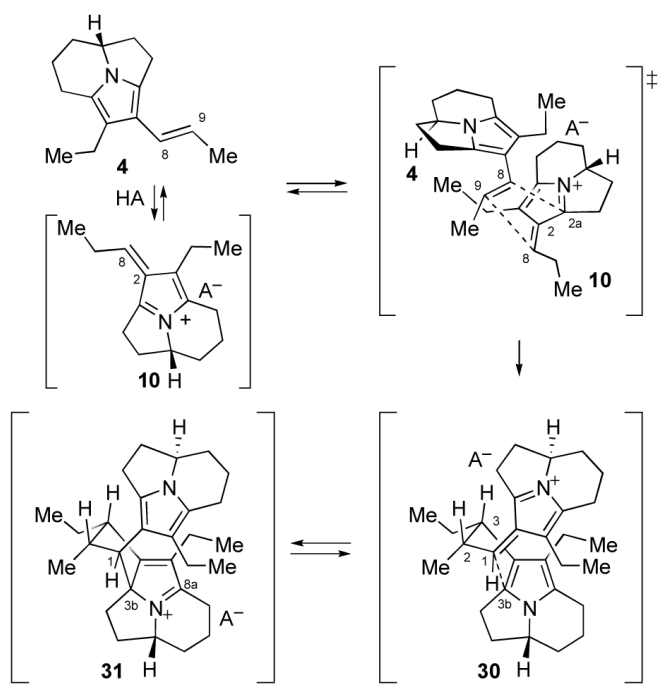

$$
-H A \mid \uparrow+H A
$$

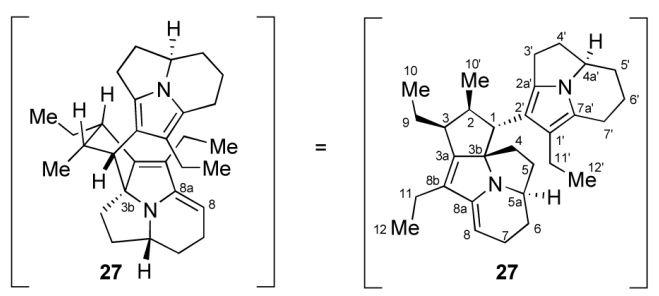

Scheme 10.

The proposed mechanism for the diastereoselective dimerization of (+)-myrmicarin $215 \mathrm{~B}$ (4) to an isomer of myrmicarin 430A (1), enamine 27 (isomyrmicarin 430A). 


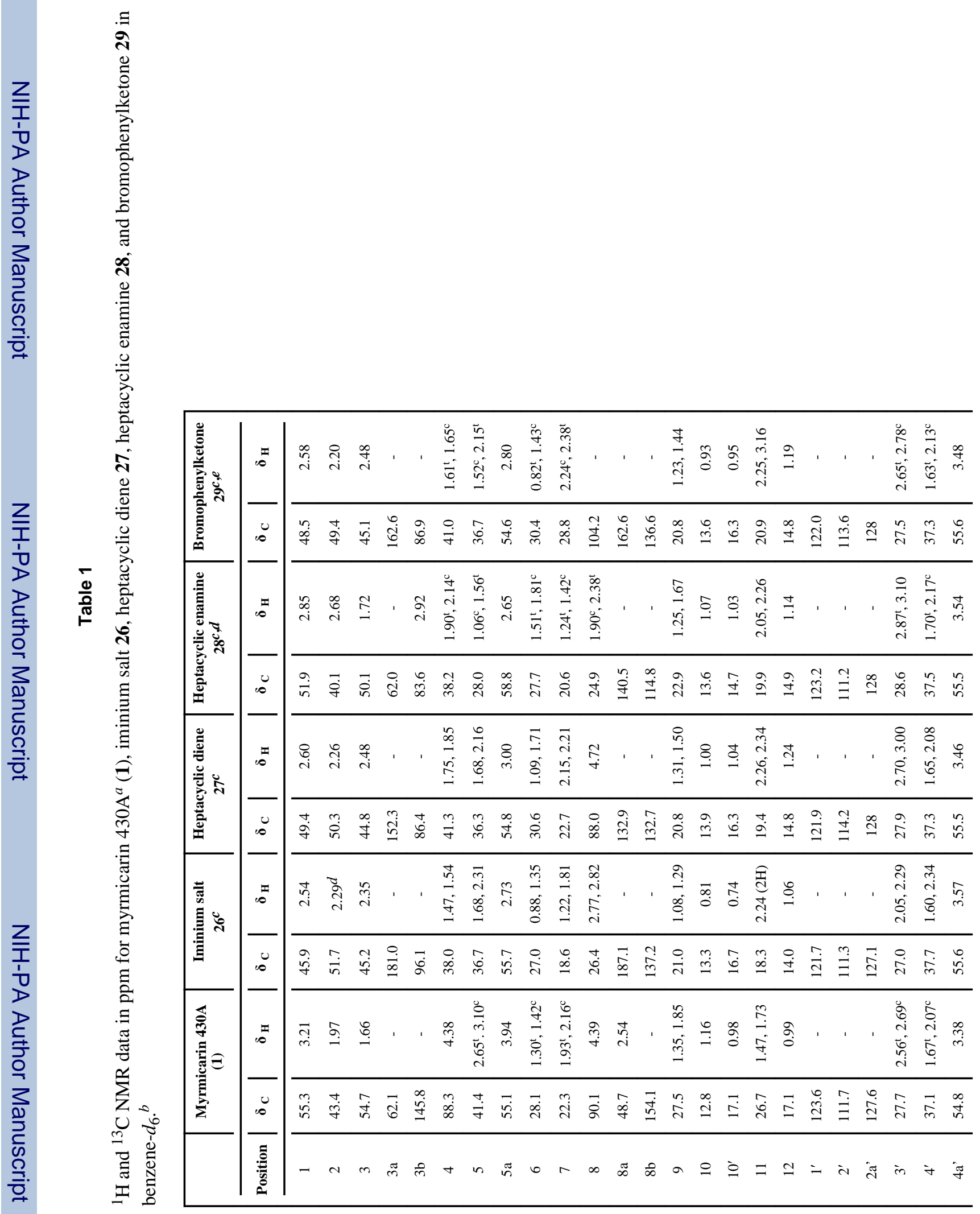




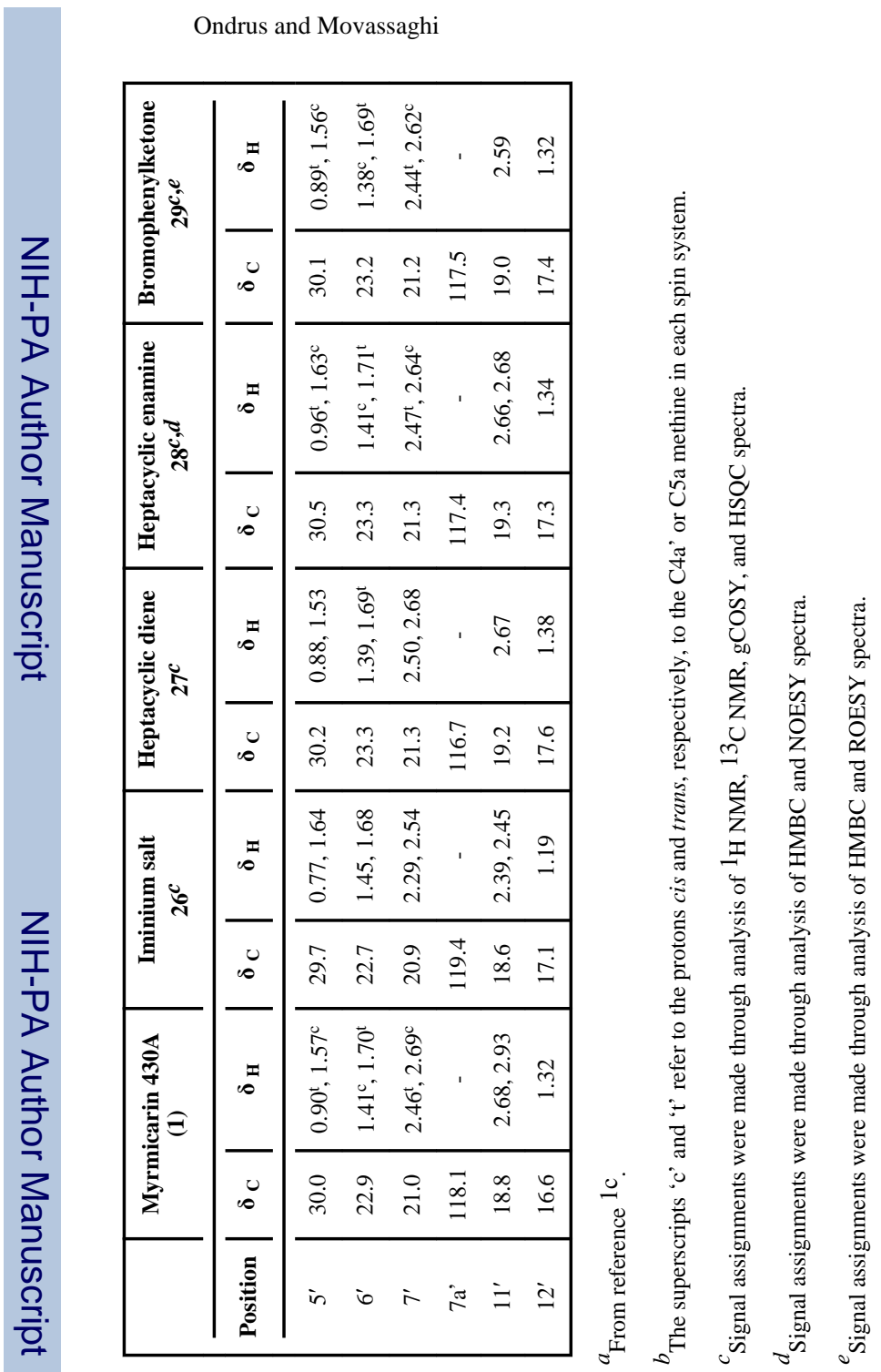

